\title{
Size-Dependent Bioactivity of Silver Nanoparticles: Antibacterial Properties, Influence on Copper Status in Mice, and Whole-Body Turnover
}

This article was published in the following Dove Press journal: Nanotechnology, Science and Applications

\author{
Ekaterina A Skomorokhova ${ }^{1,2}$ \\ Tatiana P Sankova ${ }^{3}$ \\ lurii A Orlov' \\ Andrew N Savelev ${ }^{3}$ \\ Daria N Magazenkova iD ${ }^{3}$ \\ Mikhail G Pliss ${ }^{4,5}$ \\ Alexey N Skvortsov ${ }^{3}$ \\ Ilya M Sosnin' \\ Demid A Kirilenko 1,6 \\ Ivan V Grishchuk ${ }^{3}$ \\ Elena I Sakhenberg ${ }^{7}$ \\ Elena V Polishchuk ${ }^{1,8}$ \\ Pavel N Brunkov ${ }^{1,6}$ \\ Alexey E Romanov 1,6 \\ Ludmila V Puchkova ${ }^{1-3}$ \\ Ekaterina Yu llyechova iD ${ }^{1,2}$
}

'International Research Center of Functional Materials and Devices of Optoelectronics, ITMO University, St. Petersburg, Russia; ${ }^{2}$ Department of Molecular Genetics, Research Institute of Experimental Medicine, St. Petersburg, Russia; ${ }^{3}$ Higher Engineering Physics School of the Institute of Physics, Nanotechnology and Telecommunications, Peter the Great St. Petersburg Polytechnic University, St. Petersburg, Russia; ${ }^{4}$ Department of Experimental Physiology and Pharmacology, Almazov National Medical Research Centre, St. Petersburg, Russia; 'Laboratory of Blood Circulation Biophysics, Pavlov First Saint Petersburg State Medical University, St. Petersburg, Russia; ${ }^{6}$ Center of Nanoheterostructures Physics, loffe Institute, Russian Academy of Sciences, St. Petersburg, Russia; ${ }^{7}$ Laboratory of Cell Protection Mechanisms, Institute of Cytology, Russian Academy of Sciences,

St. Petersburg, Russia; ${ }^{8}$ Telethon Institute of Genetics and Medicine, Pozzuoli, Naples, Italy
Correspondence: Ekaterina Yu llyechova Department of Molecular Genetics,

Research Institute of Experimental Medicine, Acad. Pavlov Street, 12, St. Petersburg 197376, Russia Tel +79217605274

Fax +78122322307

Email ilichevaey@itmo.ru
Purpose: The ability of silver nanoparticles (AgNPs) of different sizes to influence copper metabolism in mice is assessed.

Materials and Methods: AgNPs with diameters of 10, 20, and $75 \mathrm{~nm}$ were fabricated through a chemical reduction of silver nitrate and characterized by UV/Vis spectrometry, transmission and scanning electronic microscopy, and laser diffractometry. To test their bioactivity, Escherichia coli cells, cultured A549 cells, and C57Bl/6 mice were used. The antibacterial activity of AgNPs was determined by inhibition of colony-forming ability, and cytotoxicity was tested using the MTT test (viability, \%). Ceruloplasmin ( $\mathrm{Cp}$, the major mammalian extracellular copper-containing protein) concentration and enzymatic activity were measured using gel-assay analyses and WB, respectively. In vitro binding of AgNPs with serum proteins was monitored with UV/Vis spectroscopy. Metal concentrations were measured using atomic absorption spectrometry.

Results: The smallest AgNPs displayed the largest dose- and time-dependent antibacterial activity. All nanoparticles inhibited the metabolic activity of A549 cells in accordance with dose and time, but no correlation between cytotoxicity and nanoparticle size was found. Nanosilver was not uniformly distributed through the body of mice intraperitoneally treated with low AgNP concentrations. It was predominantly accumulated in liver. There, nanosilver was included in ceruloplasmin, and Ag-ceruloplasmin with low oxidase activity level was formed. Larger nanoparticles more effectively interfered with the copper metabolism of mice. Large AgNPs quickly induced a drop of blood serum oxidase activity to practically zero, but after cancellation of AgNP treatment, the activity was rapidly restored. A major fraction of the nanosilver was excreted in the bile with $\mathrm{Cp}$. Nanosilver was bound by alpha-2-macroglobulin in vitro and in vivo, but silver did not substitute for the copper atoms of $\mathrm{Cp}$ in vitro.

Conclusion: The data showed that even at low concentrations, AgNPs influence murine copper metabolism in size-dependent manner. This property negatively correlated with the antibacterial activity of AgNPs.

Keywords: silver nanoparticles, copper status, ceruloplasmin, alpha-2-macroglobulin, bile, urine

\section{Introduction}

Silver nanoparticles (AgNPs), which possess unique catalytic, electric, and antibacterial properties, arguably constitute the most common and widely used nanoparticulate material. ${ }^{1,2}$ Their use is particularly promoted by their antibacterial properties. AgNPs effectively suppress the growth of pathogenic unicellular microorganisms and viruses of various taxonomic groups. ${ }^{3-8}$ This property motivates the 
use of AgNPs in food and textile industry, medical devices, bone implants, and disinfectant additives used in drinking water treatment and maintenance of the antimicrobial cleanliness of pools, as well as in personal care and cosmetics. Approaches have been proposed that incorporate the use of AgNPs as therapeutic agents, and they can help overcome the resistance of bacteria to conventional antibiotics. ${ }^{9}$ Cultured human cell lines ${ }^{7}$ are typically used to evaluate the cytotoxicity of fabricated AgNPs. All cell lines tested in published reports are sensitive to AgNPs in a dose- and time-dependent manner. The biocidal and cytotoxic properties of AgNPs depend on their linear size and shape and on the cell line used and the nanoparticle coating. $^{10-17}$ In addition, AgNPs suppress the growth and development of aquatic (Danio rerio), soil (Caenorhabditis elegans), and terrestrial (Drosophila melanogaster) animals. ${ }^{18-22}$ At the same time, it is generally accepted that mammals do not display a notable sensitivity to AgNPs in vivo. ${ }^{23}$ This assumption alone justifies the wide use of AgNPs in various applications that incorporate contact with humans, and typically, no extensive toxicity tests are carried out.

The cytotoxic action of electrically neutral AgNPs can be explained by their chemical modification in living organisms, which yields reactive oxygen species (ROS) and $\operatorname{Ag}(\mathrm{I})$ coordination compounds (for simplicity, these are denoted as silver ions $\operatorname{Ag}(\mathrm{I})$ in aqueous media). ${ }^{24,25}$ ROS can damage virtually all classes of biomolecules nonspecifically, in a similar way to ionizing radiation. ${ }^{26,27}$ In organisms, a fraction of $\operatorname{Ag}(\mathrm{I})$ ions may be coordinated by thiol groups of cysteine residues, including those in metallothionein and glutathione, and this may bring them to the metabolic processes. The main approach of our study was dictated by the apprehension that AgNPs are toxic to mammals due to their ability to interfere with copper metabolism. This is because $\mathrm{Ag}(\mathrm{I})$ and $\mathrm{Cu}(\mathrm{I})$ are isoelectronic, as their external electronic layers have the same configuration $\left([\mathrm{Kr}] 4 \mathrm{~d}^{10}\right.$ and $[\mathrm{Ar}] 3 \mathrm{~d}^{10}$ respectively) and have similar ionic radii, implying that $\operatorname{Ag}(\mathrm{I})$ may be involved in copper turnover in living systems. ${ }^{28,29}$

Copper is an essential trace element, and it performs a range of physiological functions. It is required as a catalytic cofactor for vital cuproenzymes, which catalyze redox reactions (SOD1, COX, blue multicopper oxidases, lysyl oxidases, neurospecific copper oxidases, and so forth). ${ }^{30}$ Copper also serves as a modulator for the activity of various factors ${ }^{31,32}$ and takes part in the regulation of G-protein coupled receptors. ${ }^{33}$ In cuproenzymes, copper is cycled between the $\mathrm{Cu}(\mathrm{II})$ and $\mathrm{Cu}(\mathrm{I})$ states, which are both biologically important, while in regulatory proteins, it is most probably present in the $\mathrm{Cu}(\mathrm{II})$ state. $^{34}$ Biological demand for copper is combined with a high toxicity of copper ions; ${ }^{27}$ this toxicity is overcome by a system of transport proteins that carry out the safe transport of copper from the environment or food to sites of cuproenzyme formation. ${ }^{35}$ This system transports copper predominantly in its $\mathrm{Cu}(\mathrm{I})$ state. Inherited faults and ecological shifts in copper balance significantly increase the risk for neurodegenerative diseases and tumor formation. ${ }^{36}$ Faults in copper balance may also be caused by $\mathrm{Ag}(\mathrm{I})$ ions, as they are mistakenly bound by the $\mathrm{Cu}(\mathrm{I})$-binding motifs of transport proteins and brought into copper metabolism (Figure 1).

$\operatorname{Ag}(\mathrm{I})$ can appear in cuproenzymes, which contain cysteine residues in their active centers and bind to metallothioneins, ${ }^{28}$ replace copper in odorant receptors, ${ }^{33}$ form stable complexes with cysteine residues in classic zinc finger domains and zinc fingers of soluble nuclear hormone receptors. ${ }^{40}$ As a result, the enzymatic activities of cuproenzymes are impaired, while copper- and zincdependent regulatory factors lose their normal ability for specific interaction. Thus, $\operatorname{Ag}(\mathrm{I})$ causes a dysregulation of copper homeostasis and disbalance in the regulation of hundreds of genes, which may finally result in neurodegeneration and tumorigenesis.

The widespread use of AgNPs depends on their biocidal activity, which, as shown in numerous studies, depends on the particle size. In this research, we focused on investigating whether there is a relationship between the diameter of spherical AgNPs and their ability to intervene in mammalian copper metabolism, which is probably the most important ecological hazard of AgNPs for humans.

\section{Materials and Methods Fabrication of AgNPs and Their Physicochemical Characterization}

AgNPs were produced chemically by the reduction of silver nitrate by hydrazine hydrate in the presence of potassium oleate as a stabilizer. The reagents were purchased from Reakhim (Moscow Region, Russia). The size of the nanoparticles was controlled by varying the silver nitrate and potassium oleate concentrations in the reaction volume. The AgNPs were characterized by UV/ Vis absorption with a Shimadzu UV 1800 (Shimadzu, Kyoto, Japan). The structural analyses were performed using X-ray diffraction with an XRD7000 (Shimadzu, 


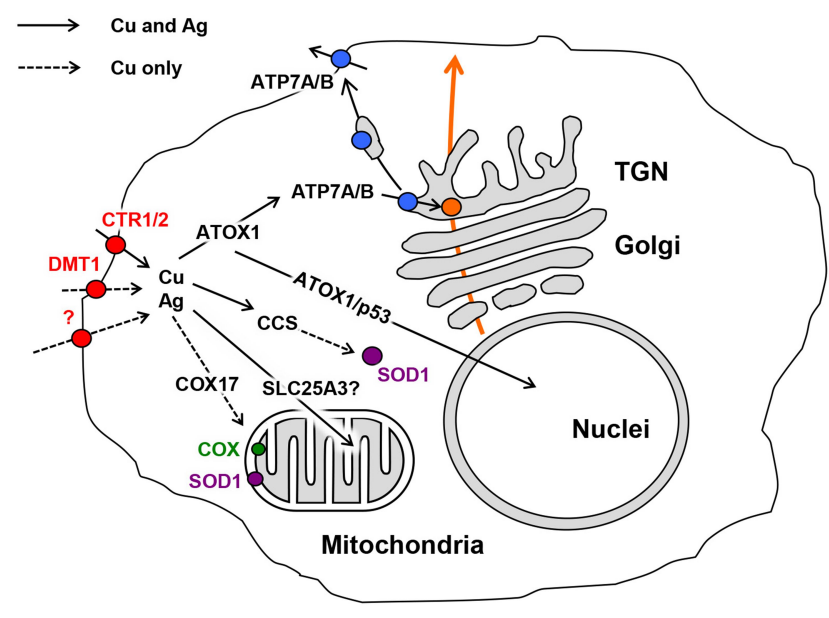

Figure I Cell compartments and the locations of cuproenzyme formation that are targeted by $\mathrm{Cu}(\mathrm{I}) / \mathrm{Ag}(\mathrm{I})$ transport; data from Puchkova et al. ${ }^{37}$ At least three proteins in the cell membrane can import silver ions to the cell, CTRI, CTR2, and DMTI, as well as an unidentified proton pump (red); data from Logeman et al, ${ }^{38}$ and Zimnicka et al. ${ }^{39}$ Inside the cell, $\mathrm{Ag}(\mathrm{I})$ is bound by the cytosolic $\mathrm{Cu}(\mathrm{I})$-chaperons ATOXI and CCS but not by COXI7. However, CCS is unable to insert $\mathrm{Ag}(\mathrm{I})$ into the active center of SODI (purple), as the ligands of the SODI active site are not favorable for $\mathrm{Cu}(\mathrm{I}) / \mathrm{Ag}(\mathrm{I}) . \mathrm{Ag}(\mathrm{I})$ ions, bound by $\mathrm{ATOXI}$, may be translocated by copper-transporting ATPases (ATP7A/B) to the lumen of the Golgi complex (TGN), which is the site of the formation of secretory cuproenzymes (orange). There, $\operatorname{Ag}(\mathrm{I})$ can be inserted into the active centers of cuproenzymes, which can favorably coordinate $\mathrm{Cu}(\mathrm{I}) / \mathrm{Ag}(\mathrm{I})$ (blue). The molecules that transport $\mathrm{Ag}(\mathrm{I})$ to the nucleus and mitochondria and correspond to silver accumulation in these compartments have not yet been identified. The solid arrows indicate established routes of $\mathrm{Ag}(\mathrm{I})$ traffic, and the dashed arrows indicate putative routes.

Abbreviations: CTRI, copper transporter I; CTR2, copper transporter 2; DMTI, divalent metal transporter I; ATOXI (Antioxidant I Copper Chaperone), copper chaperone for ATP7A/B; CCS, copper chaperone for SODI; COX I7, cytochrome c oxidase copper chaperone; $\mathrm{p} 53$, transcription factor regulating cell cycle; ATP7A/B, copper transporting PI-type ATPases (Menkes and Wilson ATPases, respectively); TGN, trans-Golgi network; SODI, cytosolic superoxide dismutase; COX, cytochrome-c-oxidase.

Kyoto, Japan) and transmission electron microscopy (TEM) using a Jeol JEM-2100F microscope (Jeol, Tokyo, Japan) at an accelerating voltage of $200 \mathrm{kV}$ at a point-to-point resolution of $0.19 \mathrm{~nm}$. The size and shape of the AgNPs were characterized using TEM or scanning electron microscopy (SEM) using Jeol JSM7001F (Jeol, Tokyo, Japan), and laser diffraction (Shimadzu, Kyoto, Japan) methods. TEM studies were performed using equipment of the Federal Joint Research Center "Material science and characterization in advanced technology" supported by the Ministry of Science and Higher Education of the Russian Federation (id RFMEFI62119X0021). The sedimentation properties of the AgNPs were evaluated as follows. The dispersion of AgNPs was centrifuged at $30,000 \times \mathrm{g}$ in Beckman Coulter Allegra-X30 (Beckman, Indianapolis, IN, USA) for $0.5,1,2,3$, and $4 \mathrm{~h}$. The completeness of sedimentation was evaluated by measuring silver concentrations in supernatant by atomic absorption spectrometry (AAS)
(ZEEnit 650P spectrometer, Analytik Jena, Germany) after the indicated periods of time. In this study, AgNP concentrations were specified as gross molar silver concentration [Ag] (moles silver per liter medium), calculated from AAS measurements, as the amount of nonparticulate silver species in AgNP samples was negligible compared to that of nanoparticle silver.

\section{Biological Objects}

In the study, bacteria, cultured human cells, and laboratory mice were used. The reagents and salts were purchased from Sigma-Aldrich (St Louis, MO, USA) or Merck (Darmstadt, Germany), unless indicated otherwise.

Escherichia coli cells of strain K802 (CGSC, New Haven, CT, USA) with the genotype $\mathrm{F}^{-}, \operatorname{lacY} 1, \lambda^{-}$, mcr $A 0, r f b C 1$, metB1, mcrB1, hsdR2 were grown aerobically in liquid or agar nutrient media based on bovine serum hydrolysate (Samson-Med, St. Petersburg, Russia) at $37^{\circ} \mathrm{C}$.

Lung cancer cell line A549, which originated from explant culture of lung carcinomatous tissue of a 58-yearold Caucasian male was provided by ATCC (Manassas, VA, USA). Cells were cultured in Dulbecco's Modified Eagle's Medium, supplemented with 10\% fetal bovine serum (Gibco, Thermo Fisher Scientific, Waltham, MA, USA) in $5 \% \mathrm{CO}_{2}$ and $37^{\circ} \mathrm{C}$ in a humidified atmosphere. Subcultivation: the cells were passaged using $0.25 \%$ trypsin with $0.02 \%$ EDTA in physiological buffer (Gibco, Thermo Fisher Scientific, Waltham, MA, USA) two or three times per week.

Male 8-week-old male $\mathrm{C} 57 \mathrm{Bl} / 6$ mice with body weights of about $25 \mathrm{~g}$ were purchased from the Rappolovo nursery (Leningrad Region, Russia). The animals were maintained in polycarbonate cages with wood shavings in a temperature-controlled facility $\left(23-25^{\circ} \mathrm{C}\right)$ under a $12: 12 \mathrm{~h}$ light-dark cycle in $60 \%$ humidity, with food and water ad libitum. Procedures involving animals and their care were conducted in conformity with institutional guidelines and followed national law (Russian Federation, Ministry of Health N267, June 19, 2003; Guide for the Use of Laboratory Animals, Moscow, 2005), which meets the requirements of the International Convention for the Protection of Animals. The studies were approved by the local Ethics Committee at the Institute of Experimental Medicine (protocol number N1/ 16, approved on March 24, 2016). 


\section{Treatment with AgNPs and Assessment of Biological Activity}

Treatment of bacterial cells. E. coli cells were taken from overnight liquid medium culture, washed with sterile water, and diluted 1:20 in a solution containing various concentrations of AgNPs. The cells were incubated at room temperature with constant shaking in an OS-20 orbital shaker (Biosan, Riga, Latvia) for various periods. Control cell samples were incubated in water. After treatment, the cells were titrated using the 10-fold dilution method to assess cell survival through colony-forming ability on agar plates. Colonies were counted after 20-24 $\mathrm{h}$ incubation at $37^{\circ} \mathrm{C}$.

Treatment of A549 cell line. Cells were seeded at a concentration of 3000 cells per well in 96-well plates. After $24 \mathrm{~h}$ preincubation, various concentrations of AgNPs ([Ag] range 30-120 $\mu \mathrm{M}$ ) were added to the growth medium, and cells were grown for 48 or $72 \mathrm{~h}$. Cell viability was evaluated by MTT assay, ${ }^{41}$ and the concentration of formazan was evaluated by CLARIOstar fluorimeter (BMG LABTECH, Ortenberg, Germany) at a $560 \mathrm{~nm}$ wavelength. The experiment was repeated three times; at each point, six replicas were made.

Treatment of mice. Four groups of mice were tested. Group 1 (control group) included at least five animals in each experiment. In experimental groups 2, 3, and 4 (35 animals in each) the mice were treated with 10, 20, and 75 nm AgNPs, respectively. AgNPs were suspended in phosphate-buffered saline (PBS; Na/K/Pi buffer, $\mathrm{pH} 7.4$, physiological ionic strength) and administered to mice in single daily intraperitoneal (ip) injections at a dose of $0.4 \mathrm{mg}$ silver $/ \mathrm{kg}$ body weight for 1 week. On the second, third, fifth, and seventh days after the first injection and 7, and 30 days after the last injection, the mice were sacrificed, and blood serum and tissue samples were obtained. Control mice of the same age were used as the reference group.

The mice were sedated with diethyl ether vapor and euthanized by cervical dislocation, which was performed by skilled personnel. The blood samples were collected from the ocular vessels, and after clot formation, the serum was separated by centrifugation at $2000 \times \mathrm{g}$ for 10 min at $4^{\circ} \mathrm{C}$. Urine and bile samples were collected by syringe (B. Brawn Group, Melsungen, Germany) from the gall bladder and urinary bladder, respectively, and centrifuged for $15 \mathrm{~min}$ at $10,000 \times \mathrm{g}$, and the supernatants were collected. The blood serum, bile, urine, and tissue samples were frozen and stored at $-80^{\circ} \mathrm{C}$ before use (Thermo Scientific $^{\mathrm{TM}}$ Forma $^{\mathrm{TM}} 900$ Series $-86^{\circ} \mathrm{C}$ Upright UltraLow Temperature Freezer, Thermo Scientific, Waltham, MA, USA). To ensure the homogeneity of the AgNP samples they were treated by ultrasound $(37 \mathrm{kHz})$ with a USB20.16/37 device (VNIITVCH, St. Petersburg, Russia) for 5 min before use. The mode of treatment used did not heat the samples and did not affect the biological or physicochemical properties of the AgNPs.

\section{Biochemical Methods Used to Assess the Effects of AgNPs on Copper Metabolism}

The oxidase activity of ceruloplasmin $(\mathrm{Cp})$ was detected using the assay-in-gel method. Blood serum aliquots (1 $\mu \mathrm{L}$ ) were fractioned in non-denaturing $8 \%$ polyacrylamide gel (PAG) electrophoresis (PAGE). Gels were stained with $o$-dianisidine to reveal $\mathrm{Cp}$ oxidase activity. ${ }^{42}$

The serum activities of alanine transaminase (ALT) and aspartate transaminase (AST) were measured. The collected samples of blood serum were used fresh or after a single defrosting. The levels of ALT and AST in serum were measured using enzymatic colorimetric method by Reitman and Frankel. ${ }^{43}$ The reactions were carried out with a fixed incubation time, as dictated by the ALT-RF and AST-RF kits (Olveks Diagnosticum, St. Petersburg, Russia). The colored products were assessed spectrophotometrically at $537 \mathrm{~nm}$ (NanoDrop 2000, Thermo Fisher Scientific, Waltham, MA, USA).

For immunoblotting analyses (WB), serum, bile, and chromatographic fractions were used. Electrophoresis was performed in $8 \%$ PAG with or without $0.1 \%$ SDS, following the Laemmli method. Protein transfer, control for the quality and uniformity of transfer with Ponceau S staining, blocking with 5\% skimmed milk, blotting with primary antibodies, and visualization of the immune complexes and their processing have been previously described. ${ }^{44}$ Hybond ECL nitrocellulose membrane, ECL reagent, ECL Hyperfilm (GE Healthcare, Chicago, IL, USA), and horseradish peroxidase-conjugated goat anti-rabbit secondary antibodies (Abcam, UK) were used for the WB analyses. Non-commercial rabbit antibodies to high-purity murine $\mathrm{Cp}\left(\mathrm{A}_{610 / 280}=0.0469\right)$ that were isolated through its interaction with neomycin were used as primary antibodies. ${ }^{45}$ Protein markers with molecular masses ranging from 14.4 to $116 \mathrm{kDa}$ were purchased from Thermo Fisher Scientific (Waltham, MA, USA). 
Gel-filtration chromatography. Blood serum samples (2 $\mathrm{mL}$ ) were fractioned using gel-filtration on a Sephadex G75 Superfine column (10-40 $\mu \mathrm{m}$; $1.6 \times 40 \mathrm{~cm}$ ) in phosphate saline buffer, $\mathrm{pH} 7.4$ (Bio-Rad, Hercules, CA, USA). The void volume of the column was estimated using blue dextran. Fractions $(\sim 1.5 \mathrm{~mL}$ per fraction) were collected and specified by $\mathrm{A}_{280}$. The relative volumes of eluted proteins with known molecular mass (Cp, serum albumin, and metallothionein) were evaluated. The volume of metallothionein elution was confirmed by immunoblotting with commercial antibodies (Abcam, Cambridge, UK).

In vitro treatment of protein samples with AgNPs. Aliquots $(500 \mu \mathrm{L}, 6 \mathrm{mg} / \mathrm{mL})$ of electrophoretically pure rat Cp A610/280 $=0.0498,{ }^{46}$ BSA (Serva, Heidelberg, Germany), and chromatographic fractions of blood serum from untreated mice, which were shown to contain silver in mice treated with AgNPs in vivo, were incubated for periods of time ranging from $1 \mathrm{~min}$ to $72 \mathrm{~h}$ with $50 \mu \mathrm{M}$ AgNPs at $15^{\circ} \mathrm{C}$. UV/Vis spectra $(250-700 \mathrm{~nm})$ were recorded before and after the sedimentation of AgNPs by centrifugation $\left(3 \mathrm{~h}, 30,000 \times \mathrm{g}, 4^{\circ} \mathrm{C}\right)$.

Determination of silver associated with $\mathrm{Cp}$ in the bile was carried out as follows. $\mathrm{Cp}$ was precipitated from bile samples by the following assay: $50 \mu \mathrm{g}$ antibodies to murine $\mathrm{Cp}$ in $50 \mu \mathrm{L}$ PBS was added to $20 \mu \mathrm{L}$ bile. This mixture was incubated overnight at $4^{\circ} \mathrm{C}$. Then $100 \mu \mathrm{g}(5 \mathrm{mg} / \mathrm{mL})$ of goat anti-rabbit antibodies (N.F. Gamaleya Institute of Epidemiology and Microbiology, Moscow, Russia) were added, and the mixture was incubated for $4 \mathrm{~h}$ at RT. The mixture was centrifuged for $15 \mathrm{~min}$ at $10,000 \times \mathrm{g}$, the supernatant was collected, and the pellet was rinsed twice with PBS and dissolved in high-purity nitric acid. Metal concentration was measured in the supernatant and in the dissolved pellet.

Common methods. Stained electrophoretic gels and membranes with visualized antigen bands, which were obtained through WB, were scanned, and the data were processed using ImageJ software (NIH, USA) and expressed in arbitrary units (a.u.). The concentrations of metal were measured using a graphite furnace AAS with a Zeeman correction of nonselective absorption using a ZEEnit 650P spectrometer. The tissue samples for AAS were dissolved in pure $\mathrm{HNO}_{3}$. All of the solutions were prepared in deionized water. The protein concentrations were measured using the Bradford assay. The data are presented as means \pm standard deviations $(\mathrm{M} \pm \mathrm{SD})$. The significance of changes was determined with unpaired two-tailed Student's t-test (StatSoft Statistica 6.0; Tulsa, OK, USA); the changes were considered significant at $P<0.05$.

\section{Results \\ Physicochemical Properties of Silver Nanoparticles}

The physicochemical properties of AgNPs produced for the present work are given in Figure 2 and Table S1. All of the produced samples displayed a single, roughly symmetrical absorption band in the UV/Vis spectrum (Figure 2A), corresponding to surface plasmon excitation of nanocrystals of metallic silver. The absorption maximum was slightly different for the obtained samples (Table S1). The average size and shape of the AgNPs were evaluated with TEM, SEM, and laser diffractometry (Figure 2B and C). The fabricated AgNPs had a spherical shape. The predominant fraction of AgNPs in the sample corresponded to diameters of 10,20 , and $75 \mathrm{~nm}$, respectively, the samples were termed AgNP10, AgNP20, and AgNP75. The size of AgNP10 could not be confirmed with laser diffractometry, as it was outside of the measurement range of the method (a lower limit of $16 \mathrm{~nm}$ ), and their size was estimated only from the TEM image. The sedimentation rate of the AgNPs was positively correlated with their size, but after $3 \mathrm{~h}$ at $30,000 \times \mathrm{g}$, almost $99 \%$ of initial atomic silver content was sedimented, irrespective of the AgNP size (Figure 2D). The AgNP suspensions were stable over a year of storage, their color did not change, and no agglomeration was observed.

\section{Antibacterial Properties of AgNPs}

The primary commercial value of AgNPs is their antibacterial activity, so the obtained AgNPs were tested for toxicity in E. coli cells. All of the AgNP samples displayed dose- and time-dependent activity. The strongest antibacterial activity was observed for the smallest nanoparticles, AgNP10. When a $20 \mu \mathrm{M}$ silver concentration was used, the antibacterial effects of AgNP10 were already obvious after $0.5 \mathrm{~h}$ exposure (Figure 3A). After $3 \mathrm{~h}$ treatment, the colony-forming ability of bacterial cells dropped by more than 3 orders of magnitude (Figure 3B), and the surviving cells formed untypically small colonies. After $24 \mathrm{~h}$ cell exposure to AgNP10, the colony-forming ability was undetectable. The antibacterial effects of AgNP75 were less profound and were observed only after 
AgNP10

A

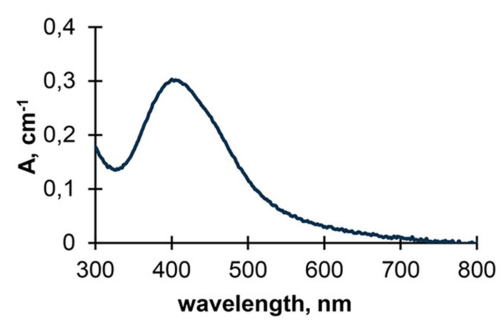

B

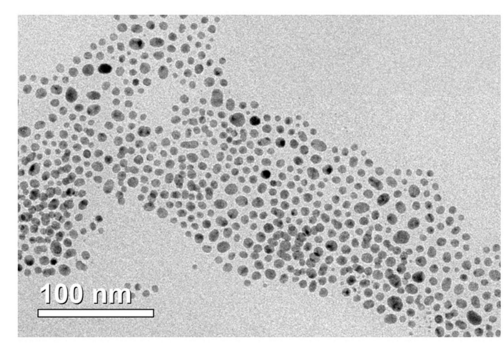

C

D

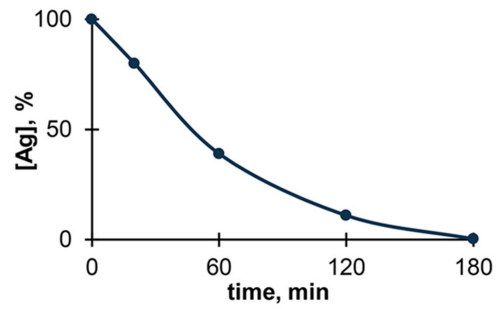

AgNP20
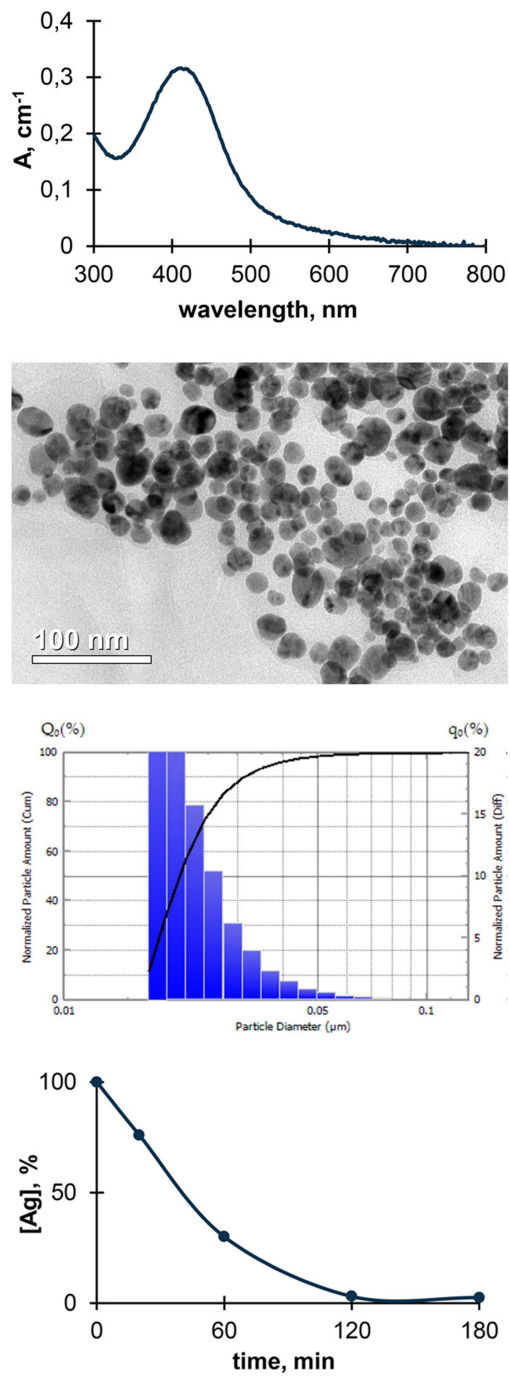

AgNP75
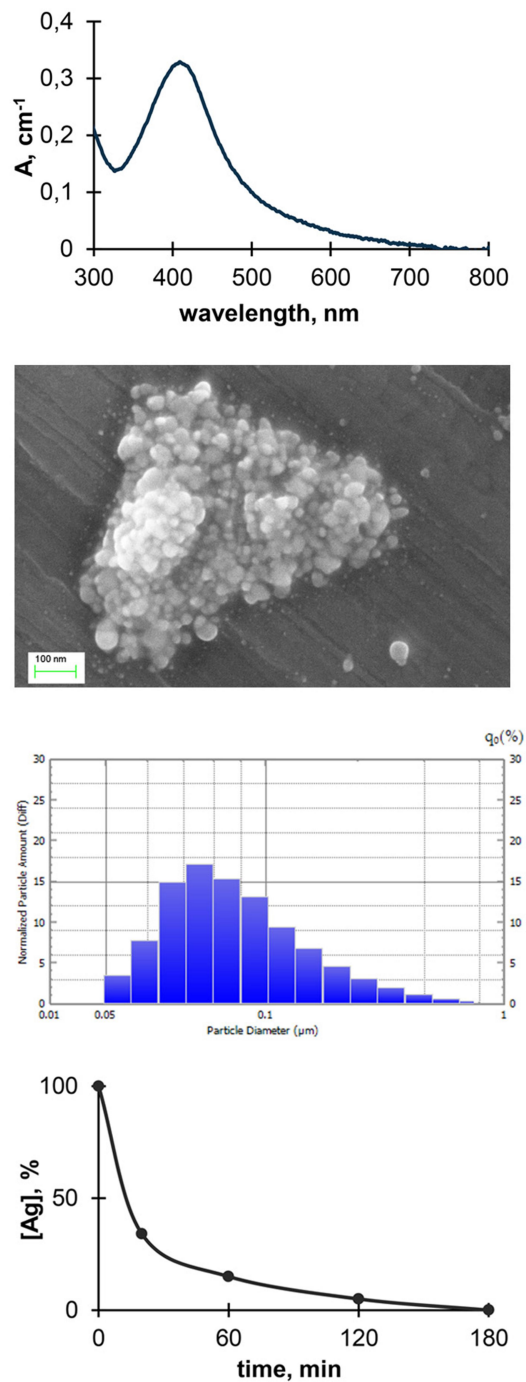

Figure 2 Some physicochemical properties of fabricated AgNPs. Columns correspond to AgNPs of different sizes: (A) UV/Vis absorption spectra of aqueous suspensions of AgNPs; (B) images of AgNPs obtained by transmission (AgNPI0 and AgNP20) or scanning electron microscopy (AgNP75); (C) distribution of the AgNPs by their diameter as measured using laser diffractometry; (D) sedimentation of AgNPs during centrifugation; abscissa, time, min; ordinate, \% of initial silver content in the supernatant suspension.

$3 \mathrm{~h}$ treatment, and the colony-forming ability was still detected after $24 \mathrm{~h}$ treatment, amounting to $10^{-2}$ to $10^{-3}$ of the initial (untreated) value.

The antibacterial action of AgNP20 can be characterized as intermediate. It was observable after $2 \mathrm{~h}$ exposure, and after $24 \mathrm{~h}$, the colony-forming ability was lower by 4 orders of magnitude. When the nanoparticle concentration was increased 10-fold, significant antibacterial effects could be observed for all fabricated AgNPs after 0.1 $\mathrm{h}$ exposure (Figure 4). The absence of colonies in the first 10-fold dilution and their presence in further dilutions (Figure 4A) can be explained by the presence of a significant amount of AgNPs from the incubation medium in the first dilution $(20 \mu \mathrm{M})$, which continued to produce toxicity on the plate.

One hour incubation with AgNPs at $[\mathrm{Ag}] 200 \mu \mathrm{M}$ was enough to achieve a full biocidal effect (decrease in colony-forming ability by $>5$ orders of magnitude) of all of the AgNP samples. AgNP20 displayed significantly lower antibacterial properties than AgNP10, despite the small difference in size. The lowest toxicity was observed for the largest nanoparticles. These results, summarized in Table S2, confirm the modern conception that at a given atomic silver concentration, smaller nanoparticles show 


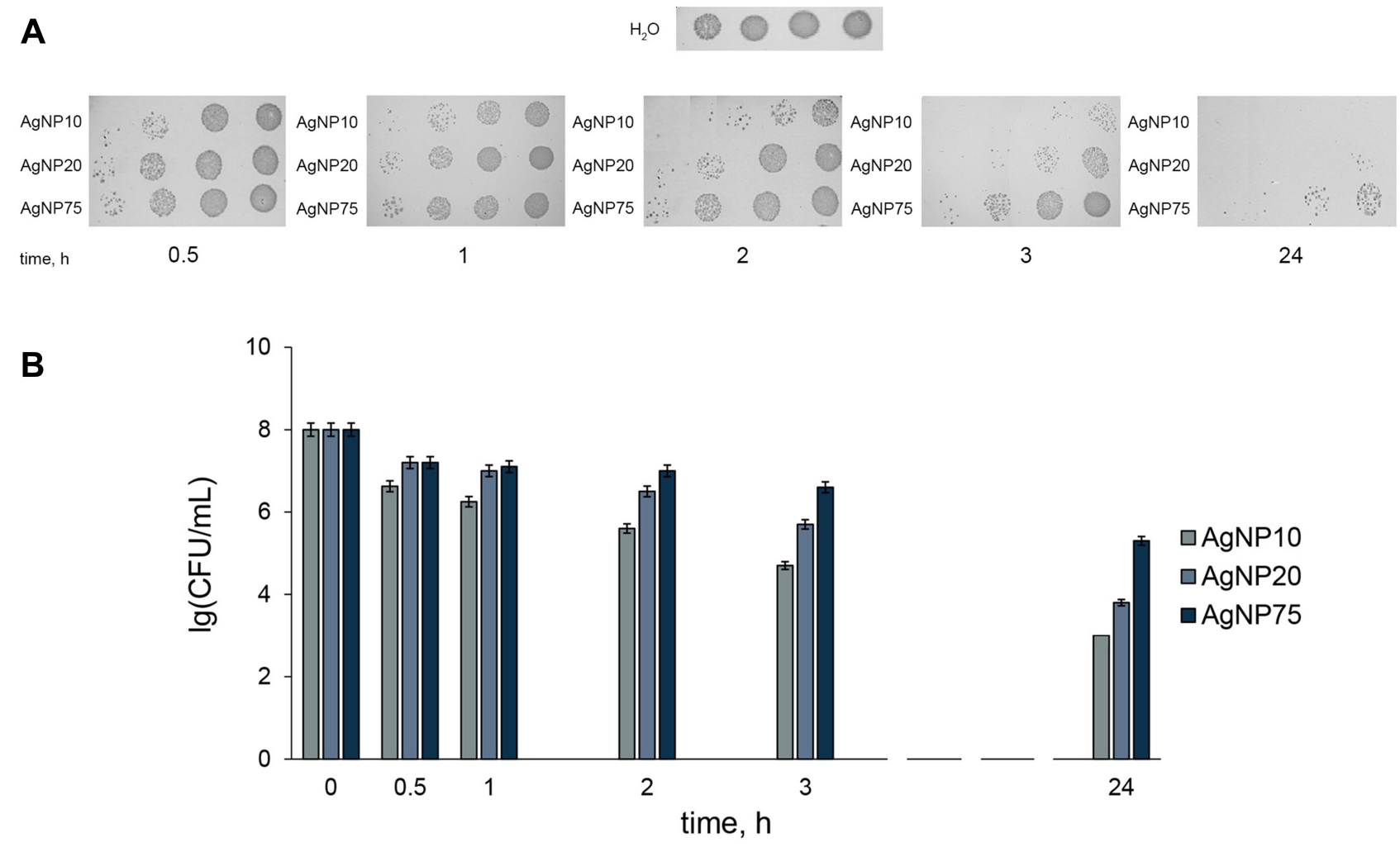

Figure 3 Time-dependent antibacterial effects of the AgNPs at [Ag] $20 \mu \mathrm{M}$. (A) colony-forming ability of Escherichia coli cells on agar plates at various times of incubation with AgNPs of different size; (B) bar charts showing survival of $E$. coli cells as a function of time of treatment with AgNPs. CFU - colony-forming unit.

higher toxicity, both for Gram-positive and Gram-negative bacteria. $^{9,14}$ This effect is usually related to the larger total surface area of smaller nanoparticles, which, at constant gross concentrations of silver in the medium, is inversely proportional to particle diameter.

All AgNPs inhibited the metabolic activity of A549 cells in accordance with dose and time, but no pronounced correlation was found between cytotoxicity and nanoparticle size (Figure S1). As expected, cultured A549 cells were generally more tolerant of AgNPs than bacterial cells.

\section{Intervention of AgNPs in Murine Copper Metabolism}

In animal models in vivo, AgNPs have been used at concentrations ranging from $\sim 2.25-14 \mathrm{mg} / \mathrm{kg}$ body weight daily (producing no toxic effects after prolonged exposure) to $50.0-500 \mathrm{mg} / \mathrm{kg}$ body weight daily (with a toxic effect observed after a week of injections or in a subchronic oral load). ${ }^{47-51}$ It is difficult to imagine an ordinary situation in which a person would be exposed to a silver dose that is $>10 \mathrm{mg} / \mathrm{kg}$ body weight. For this reason, we used low dose exposures. Mice were treated with AgNPs at doses of $0.4 \mathrm{mg}$ silver $/ \mathrm{kg}$ body weight daily for 7 days.

\section{Copper and Silver Distribution in Mice, Treated with AgNPs}

All of the experimental animals appeared to be healthy during the period of the AgNP treatment and for 1 month after the injections were cancelled. Mortality was completely absent during this period. The appetite, behavior, emotional state, and body weight of the animals did not change during the experiment. The levels of ALT and AST matched the range for healthy adult $\mathrm{C} 57 \mathrm{Bl} / 6$ mice, that is, 20-60 U/L for ALT and 35-90 U/L for AST, according to the literature (Table S3).$^{52,53}$ In mice injected with AgNP20 and AgNP75 for 1 week, dark inclusions were observed in the mesentery (Figure 5A). These inclusions were not observed in mice that received AgNP10. Atomic silver concentrations were measured in the samples from the central (square 3) and peripheral (squares 2 and 1, respectively) areas of the inclusion. The results show that the central area of the inclusion was enriched with silver compared to the surrounding tissue (Figure 5B).

The organs of mice in all of the experimental groups displayed an accumulation of silver (Figure 5C). The specific concentrations of silver significantly varied between organs but did not depend on the size of the 
A
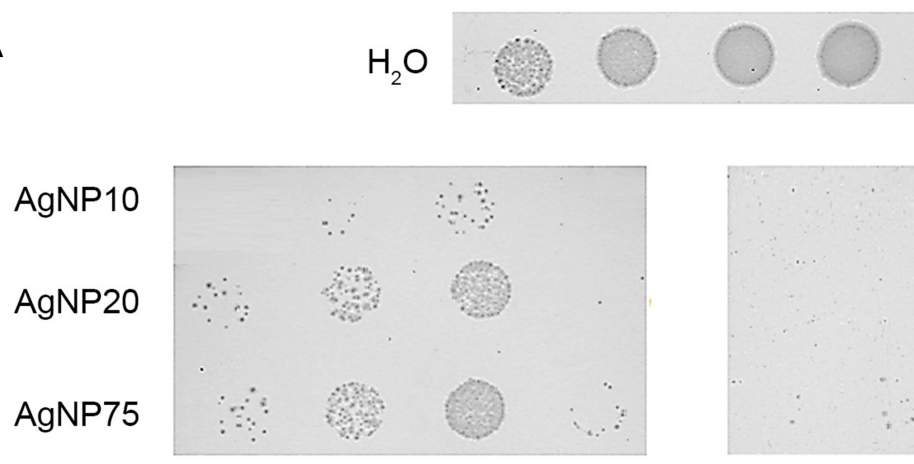

time, $\mathrm{h}$

0.1

0.5

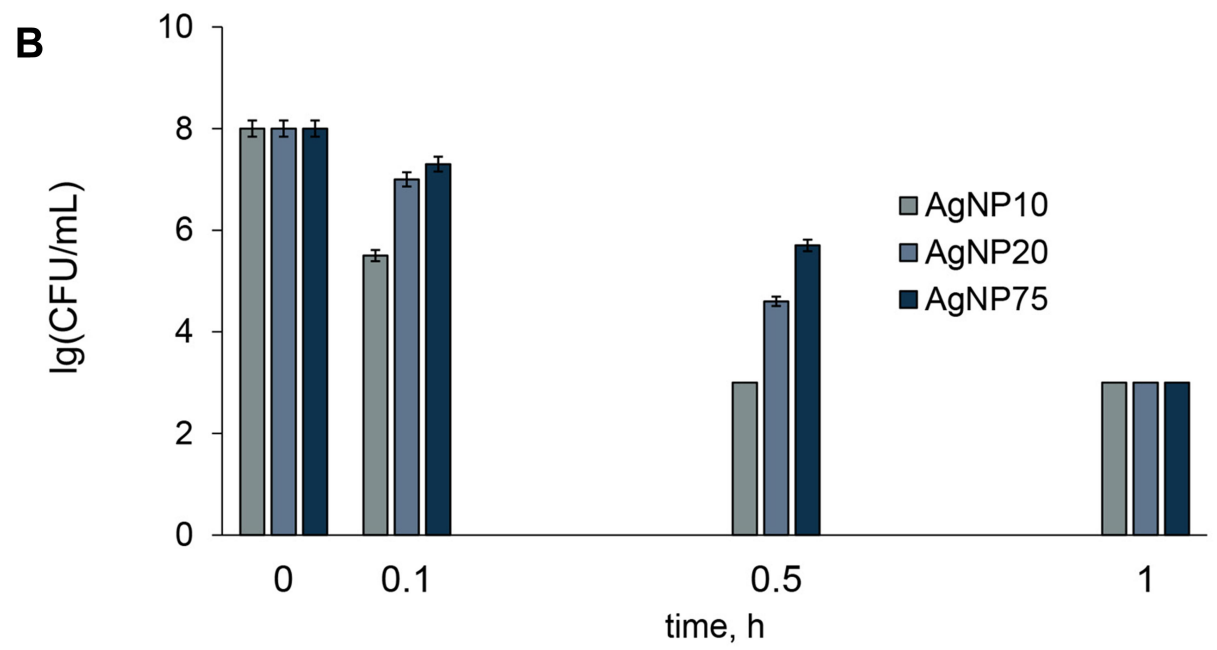

Figure 4 Time-dependent antibacterial effects of the AgNPs at $[\mathrm{Ag}] 200 \mu \mathrm{M}$. (A) Escherichia coli colony-forming ability on agar plates at various periods of incubation with AgNPs of different size; (B) bar charts showing survival of E. coli cells as a function of time of treatment with AgNPs. CFU - colony-forming unit.

administered AgNPs. The highest accumulation levels were observed in the liver, spleen, and lungs. In the kidneys, heart, and brain, silver was accumulated to a lower extent (the organs are listed in descending order of specific silver concentration), but the concentrations were still significantly higher than the background level in untreated mice. These results are consistent with the distribution of silver in mice after single intravenous injection of AgNPs. ${ }^{54}$ A relatively large standard deviation was observed for silver concentration in the liver. This may be explained by the different time of AgNP absorption among animals of the same group. ${ }^{49}$

In parallel, we measured copper concentrations in all abovementioned organs. The results in Figure 5D indicate that 7 days of AgNP injections for did not affect copper levels in tissues. In these measurements, the in-group variance was relatively low. There was no obvious correlation between copper concentrations in the organs and the ability to accumulate silver (compare Figure 5C and D). The liver, heart, and brain had high copper levels, but unlike the liver, the heart and brain accumulated silver poorly. Meanwhile, the spleen, which had low copper content, accumulated silver effectively.

\section{Influence of AgNPs on Copper Status Indexes of Blood Serum in Mice}

Silver was readily found in the blood serum of mice after 1 day, following the first injection of AgNPs (Figure 6A). For each type of AgNP, the silver content in blood serum remained relatively constant over the 7 days of treatment. This may indirectly indicate that nanoparticle silver was cleaned from the bloodstream, and the observed silver concentration was in a dynamic equilibrium between entrance, excretion, and corpuscle 

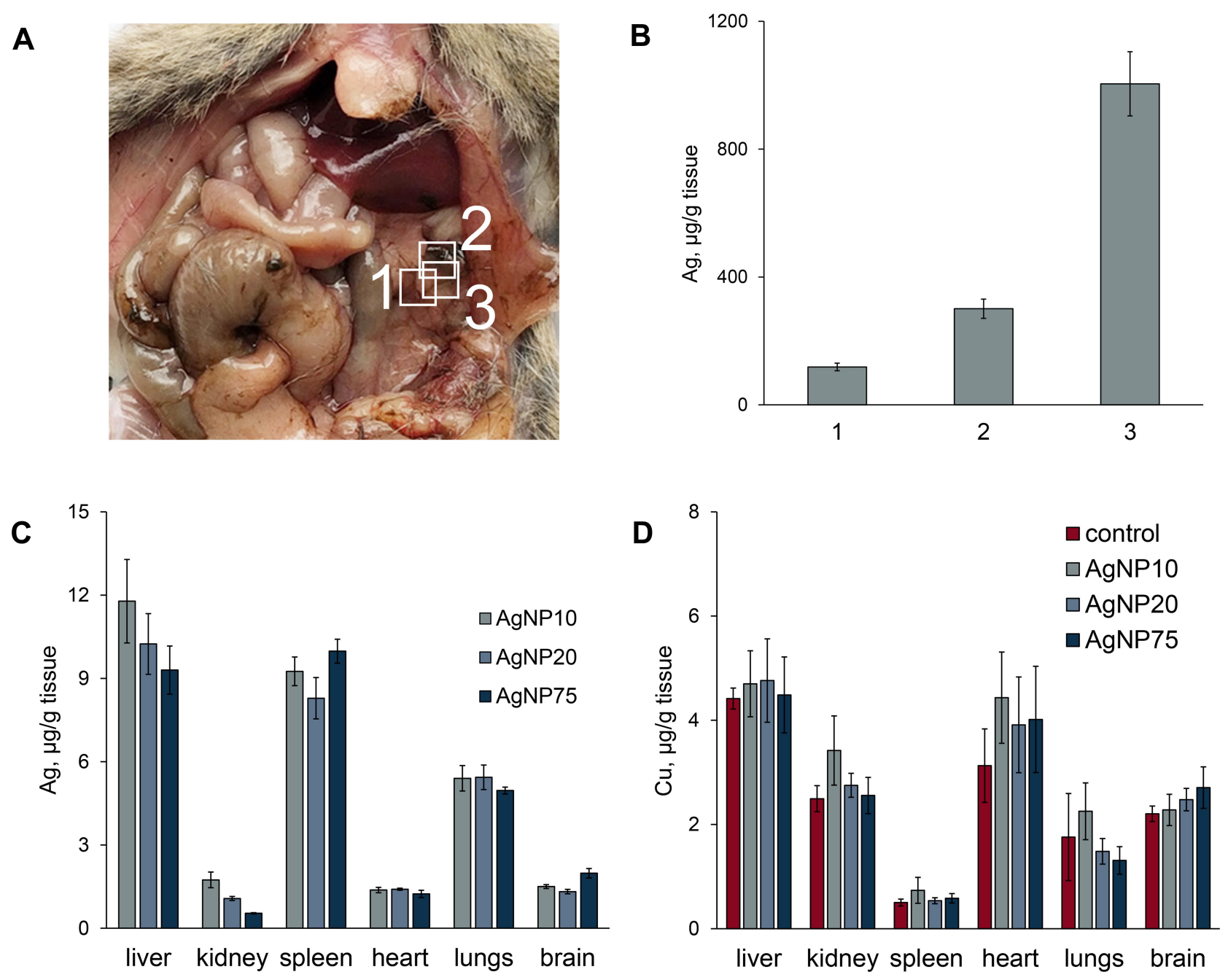

Figure 5 Copper and silver distribution in murine body during treatment with AgNPs. (A) dark silver-containing inclusions in mesentery. (B) silver content in the inclusions and surrounding tissue, I) regular spotless tissue, 2) periphery of the spot, 3) central part of the spot. (C) silver and (D) copper concentrations in different organs ( $\mu$ g/g tissue) after daily AgNP injections for seven days. In the organs of the control mice, silver content did not exceed $10 \mathrm{ng} / \mathrm{g}$ tissue.

formation. The concentration of silver in blood serum decreased a week after the end of injections (days in Figure 6 are counted from time of the first injection, so the point under discussion was day 14 of the experiment). Residual silver could still be detected in the blood sera of all of the treated mice for more than a month after the injection was cancelled (Figure 6A). The copper concentrations decreased up to the seventh day of the injections (Figure 6B). After the injections were cancelled, the serum copper levels completely recovered to their normal levels in the following week (Figure 6B). In the blood serum of all experimental groups, $\mathrm{Cp}$ oxidase activity decreased, and the dynamics of this process corresponded to a drop in copper concentration (Figure 6C). At corresponding times and at cumulative silver doses, AgNP75 treatment almost entirely inhibited $\mathrm{Cp}$ oxidase activity, while AgNP10 and AgNP20 treatment induced a drop in $\mathrm{Cp}$ activity to $\sim 30 \%$ of its reference level in the control group. The concentration of $\mathrm{Cp}$ polypeptides in blood serum did not significantly change during the experiment, as evidenced by immunoblotting (Figure 6D).

To analyze the association between copper and silver concentrations and serum proteins, the blood sera were fractionated by gel-filtration with subsequent measurements of copper and silver concentrations, oxidase activity, and immunoreactive $\mathrm{Cp}$ content in the chromatographic fractions.

Most of the copper was localized at a single peak (Figure 7A). This peak was well co-localized with maximum of oxidase activity and immunoreactive $\mathrm{Cp}$ content (Figure 7A, insert). There was a minor shoulder on the copper peak, which eluted just after the major peak and 

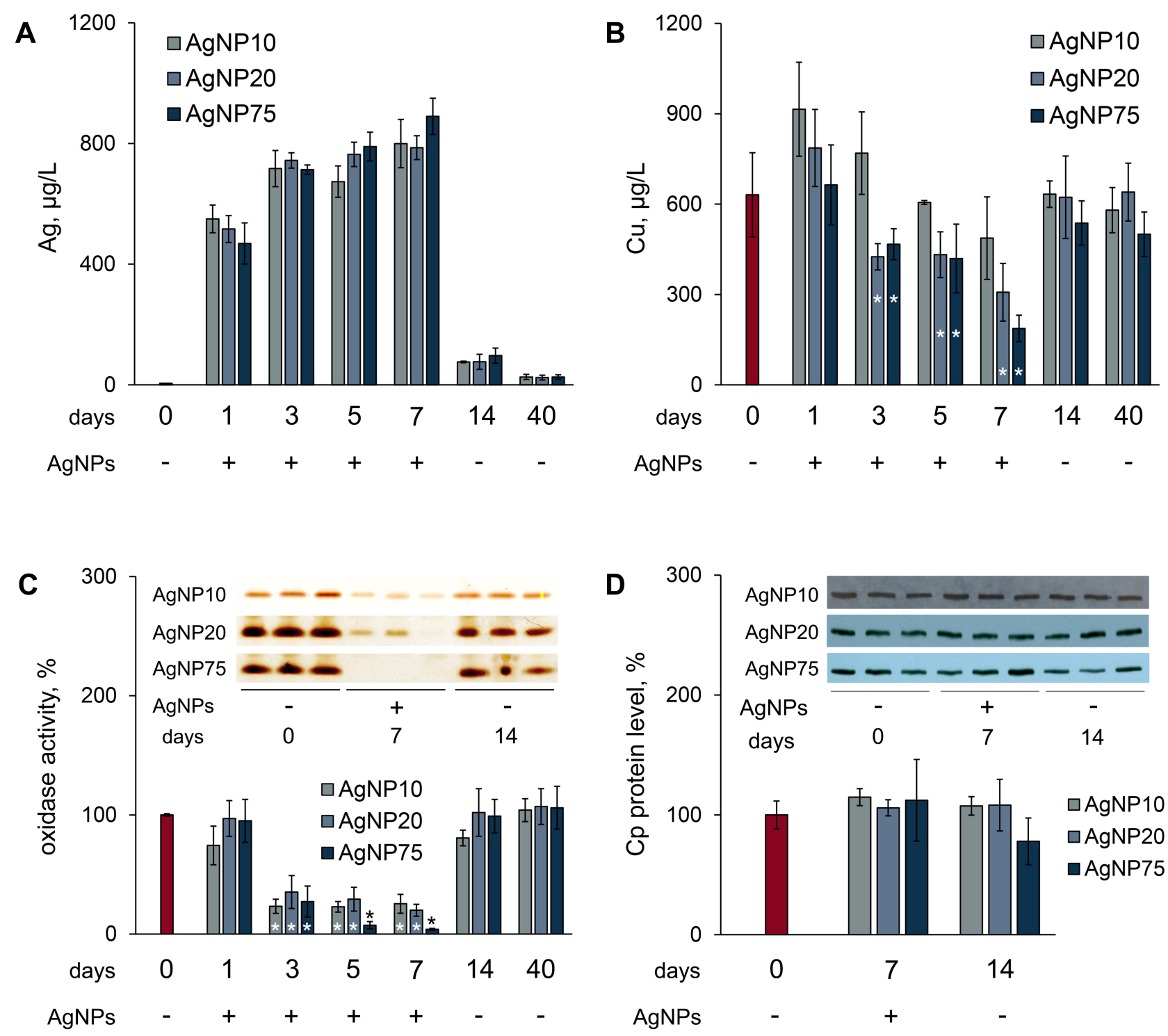

Figure 6 Influence of AgNP treatment on copper status indexes in mice. (A) and (B)-concentrations of silver and copper in blood serum, where red bar denotes control (untreated) mice (C) Cp oxidase activity of blood serum of treated mice, where red bar denotes control mice; ordinate, oxidase activity, \% of control ( $n=5$ animals per group). Inset: image section of gel, stained by o-dianisidine, I $\mu \mathrm{L}$ serum per lane, samples from three random mice in each group. (D) $\mathrm{Cp}$ protein content, \% from control. Inset: immunoblotting of blood sera $(0.2 \mu \mathrm{L}$ per lane) with antibodies to $\mathrm{Cp}$, the samples are the same as in section (C), abscissa, days after the first injection. *value differs from control group at the $P<0.05$ level.

corresponded to fraction \#16, where immunoreactive Cp was not present. This shoulder may indicate copper that is bound to serum albumin. Albumin binds $\mathrm{Cu}(\mathrm{II})$ and can account for up to $5-10 \%$ of $\mathrm{Cu}(\mathrm{II})$ in serum. In mice that received AgNP75 injections, $\mathrm{Cp}$ was eluted similarly to control (Figure 7B), and its peak was co-localized with peaks in the copper and silver profiles. The silver profile also displayed a peak in fractions 4-6, which corresponded to large proteins and protein complexes $(>200 \mathrm{kDa})$. The largest concentration of silver was observed in fraction \#5. Neither traces of immunoreactive $\mathrm{Cp}$ nor atomic copper could be detected in this fraction.

\section{Interaction of AgNPs with $C_{p}$ and Other Serum} Proteins in vitro

A series of experiments was conducted to evaluate the ability of AgNPs to interact directly with blood serum proteins, which were associated with silver in the blood serum of mice treated with AgNPs in vivo. Electrophoretically pure rat $\mathrm{Cp}\left(\mathrm{A}_{280 / 610}=0.049\right)$ was used as an example of serum protein, which binds silver metabolically. ${ }^{55}$ A highly pure commercial sample of bovine serum albumin (BSA) was used as the reference protein. BSA is not a proper metalloprotein, but it does contain coordination domains equipped with sets of donor 

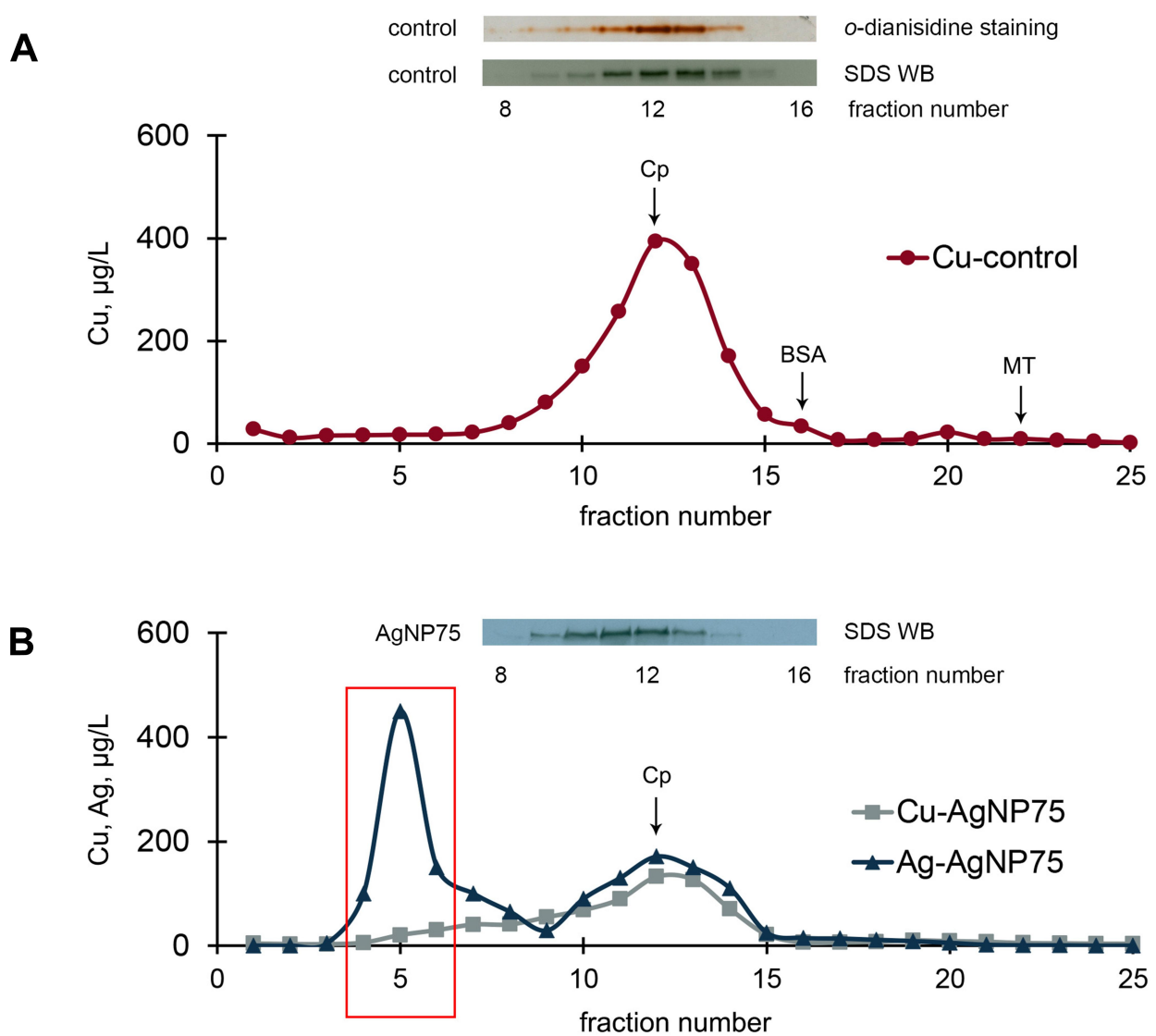

Figure 7 Chromatographic profiles (gel-filtration) of copper and silver distribution in blood serum of untreated mice (A) and mice treated with AgNP75 (B); 2 mL of serum were loaded on the column. Inserts: oxidase activity and immunoreactive $C_{p}$ in the fractions.

groups appropriate for the physiological ions $\mathrm{Cu}(\mathrm{II}), \mathrm{Zn}$, $\mathrm{Ni}(\mathrm{II})$, and $\mathrm{Co}(\mathrm{II})$, as well as toxic cadmium. A physiological function of mammalian serum albumin is binding of $\mathrm{Cu}$ (II) absorbed in the intestine and transport of $\mathrm{Cu}(\mathrm{II})$ to the liver. ${ }^{56-58}$ In vivo albumin does not bind silver from AgNPs, as indicated by the data in Figure 7B. The gel-filtration fractions \#4-6 of blood serum from untreated control mice (corresponding to fractions marked by a rectangle in Figure 7B, were tested for their ability to interact with AgNPs in vitro.

The experiment was conducted as follows: (1) UV/Vis absorption spectra were recorded from dispersions of nanoparticles and protein solutions in buffer, which indicated blood serum $\mathrm{pH}$; (2) AgNP dispersions were mixed with protein solutions and incubated for various time intervals; (3) the absorption spectrum of the mixture was recorded; (4) and the mixtures were centrifuged for $3 \mathrm{~h}$ and the spectrum of the supernatants were recorded. The proteins were also analyzed by electrophoresis after the incubation. The details are given in the Methods section. The absence of low-molecular-weight silver species in AgNP samples and the centrifugation conditions for the complete sedimentation of AgNPs are supported by the data given in Figure 2 and Table S1. It was assumed that the specific interaction between nanoparticles and proteins caused a change in the spectral features of AgNPs and/or proteins. The absence of spectral changes was considered to indicate an apparent absence of interaction between $\mathrm{Ag}(\mathrm{I}) / \mathrm{AgNPs}$ and the protein. Experiments were done for all of the studied AgNP samples. Because the results were similar for all of the studied sizes, only data for AgNP75 (having the most potent in vivo influence on mammalian copper metabolism) are presented.

$\mathrm{UV} / \mathrm{Vis}$ spectra for $\mathrm{Cp}$ and BSA are given in Figure 8A and B. Each component is easily identified by a specific absorption band. Initial AgNP75 dispersion displays a plasmon band at $413 \mathrm{~nm}$ (Figure 2, Table S1), albumin and serum fractions \#4 and \#5 absorb at $280 \mathrm{~nm}$ (Figure 8A, E, F), and Cp (Figure 8B) absorbs at $280 \mathrm{~nm}$ and 610 $\mathrm{nm}$ (blue copper). UV/Vis spectra for the mixtures of AgNPs with protein samples after various times of incubation (from 0 to $72 \mathrm{~h}$ ) were recorded before and after 

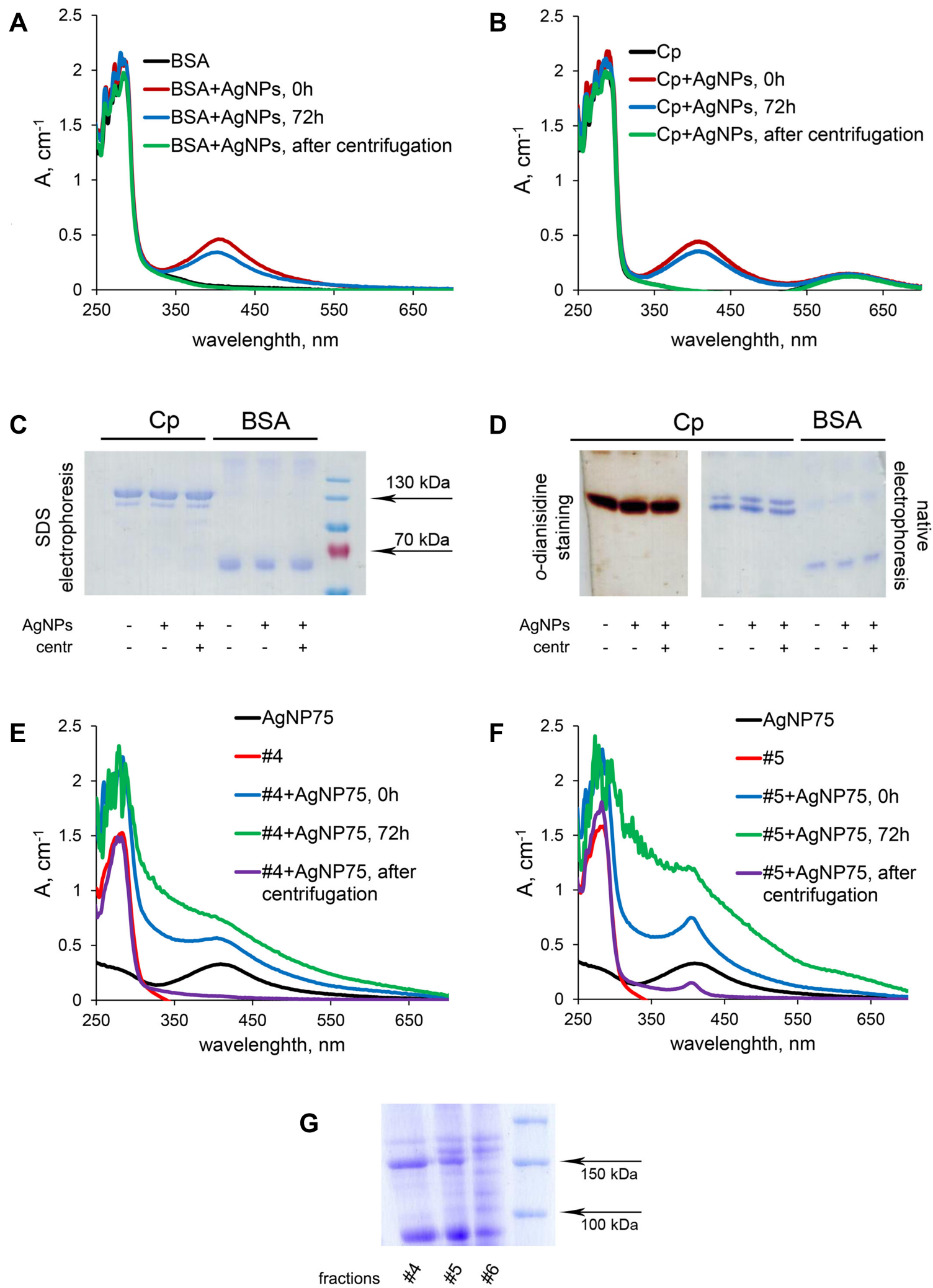

Figure 8 Interaction of AgNPs with BSA (A) and CP (B) in vitro studied with UV/Vis spectroscopy. (C) PAGE in denaturing reducing conditions of Cp and BSA. (D) nondenaturing PAGE of CP (o-dianisidine staining) and BSA (Coomassie staining), with changes in UV/Vis spectra of serum fractions \#4 (E) and \#5 (F) during incubation with AgNPs. (G) PAGE in denaturing reduced conditions of blood serum fractions \#4-6 from control mice. 
centrifugation. Incubation did not affect the spectral properties, so only the data for the longest incubation time $(72 \mathrm{~h})$ are presented. The data presented in Figure 8A and $B$ indicate that the UV/Vis spectra of the AgNPs, $\mathrm{Cp}$, and BSA did not change from the initial values. $\mathrm{Cp}$ and BSA protein contents did not decrease in the supernatant after centrifugation at $30,000 \times \mathrm{g}$ for $3 \mathrm{~h}$, and their electrophoretic mobility in PAGE (denaturing reducing conditions) also did not change. No traces of protein fragmentation were observed (Figure 8C), Cp entirely retained its oxidase activity in non-denaturing PAGE gels, and the ratio of apo- and holo-forms were conserved (Figure 8D). Thus, it was concluded that silver from AgNPs was not able to displace copper atoms from $\mathrm{Cp}$ or otherwise impair the active $\mathrm{Cp}$ centers in vitro.

The spectra of protein fractions \#4 (Figure 8E) and \#5 (Figure $8 \mathrm{~F}$ ) were already changing during mixing with the AgNP sample (less than $1 \mathrm{~min}$, denoted as $0 \mathrm{~h}$ in Figure 8). During incubation, the spectra progressively changed such that at $72 \mathrm{~h}$, the nanoparticle peak at $413 \mathrm{~nm}$ was flattened, while the light scattering of the mixture significantly increased. Centrifugation of the $\# 4 / \mathrm{AgNP}$ mixture removed spectral features and scattering components completely, while in the $\# 5 / \mathrm{AgNP}$ mixture, some spectral features at $\sim 400 \mathrm{~nm}$ remained in the supernatant. It is possible that the copper-binding sites of some polypeptides in fraction $\# 5$ caused proteins to stick to AgNPs. This decreased the effective density of the particles and the respective rates of their sedimentation, so that the spectral features of AgNPs could not be removed by centrifugation that was sufficient to precipitate original AgNPs.

The observed effects support the assumption that the proteins from blood serum fractions $\# 4$ and $\# 5$ interact with AgNPs. In fraction \#6, incubation with AgNPs did not induce any notable spectral changes. PAGE conducted in denaturing conditions showed the presence of a major polypeptide in fractions \#4 and \#5, which was absent from fraction \#6. This polypeptide was tentatively assigned by predominance and molecular mass to a subunit of $\alpha$ 2 -macroglobulin $(\alpha 2 \mathrm{MG})^{60}$ that can bind both copper and silver. $^{61}$

\section{Silver is Excreted in the Bile}

The most important factor of AgNP toxicity is the rate by which silver clears from the organism. Excretion was evaluated by measuring silver concentration in the liver tissue, urine, and bile (Figure 9). In the liver, silver from nanoparticles of different sizes was cleared at similar rates
(Figure 9A). The amount of silver was significantly reduced by day 40 of the experiment, but complete clearing was not observed in any of treated group (Figure 9A). In the samples of urine for all groups, including untreated mice, copper was practically absent (an average value of about $5 \mu \mathrm{g} / \mathrm{L}$ ). After seven AgNP injections, silver was found in urine samples of all treated mice (Figure 9B). In the bile, the copper concentration of the control mice was approximately $300 \mu \mathrm{g} / \mathrm{L}$. This value slightly decreased in mice treated with AgNPs $(\sim 250 \mu \mathrm{g} / \mathrm{L})$. These data agree with the proven concept that the bile is the main route for copper excretion in adult mammals. ${ }^{60}$ In mice treated with AgNPs, the silver concentration in the bile was more than 200 times higher than in urine (Figure 9C), indicating that silver is excreted mainly through the bile, similarly to copper.

Human and rat bile both contain $\mathrm{Cp}$, which takes part in copper excretion. ${ }^{61,62}$ To assess the association between silver in the bile and $\mathrm{Cp}$, we measured silver concentration in Cp immunoprecipitates. The data in Figure 9D indicate that about half of the copper and silver in bile samples were bound to $\mathrm{Cp}$. WB analyses of non-denaturing electrophoretic gels revealed two molecular forms of immunoreactive $\mathrm{Cp}$ in the bile (Figure 9E). One of these corresponded to blood serum $\mathrm{Cp}$, but the other was not present in serum.

\section{Discussion}

In this study, AgNPs of three different sizes were fabricated by adjusting the component ratio of the reaction mixture, in which $\operatorname{Ag}(\mathrm{I})$ was chemically reduced. Smaller (AgNP10 and AgNP20) and larger (AgNP75) nanoparticles were obtained. The nanocrystal structure of AgNPs was confirmed by UV/Vis spectroscopy. The shape and size were determined with TEM, SEM, and laser diffractometry. The samples contained no traceable amount of silver ions or low-molecular-weight silver compounds, as confirmed by the absence of silver (measured with AAS) in supernatant after centrifugation (Figure 2D). $\mathrm{Ag}(\mathrm{I})$ ions and AgNPs act in biological systems through different mechanisms. ${ }^{64}$ The absence of silver ions in the samples was very beneficial, as it allowed us to eliminate any potential interference from $\operatorname{Ag}(\mathrm{I})$ ions. In general, the samples differ only in terms of nanoparticle diameter, which may be used to evaluate the importance of this factor for various modes of biological activity. They were estimated for biocidal activity, cytotoxicity, and ability to influence copper status. 

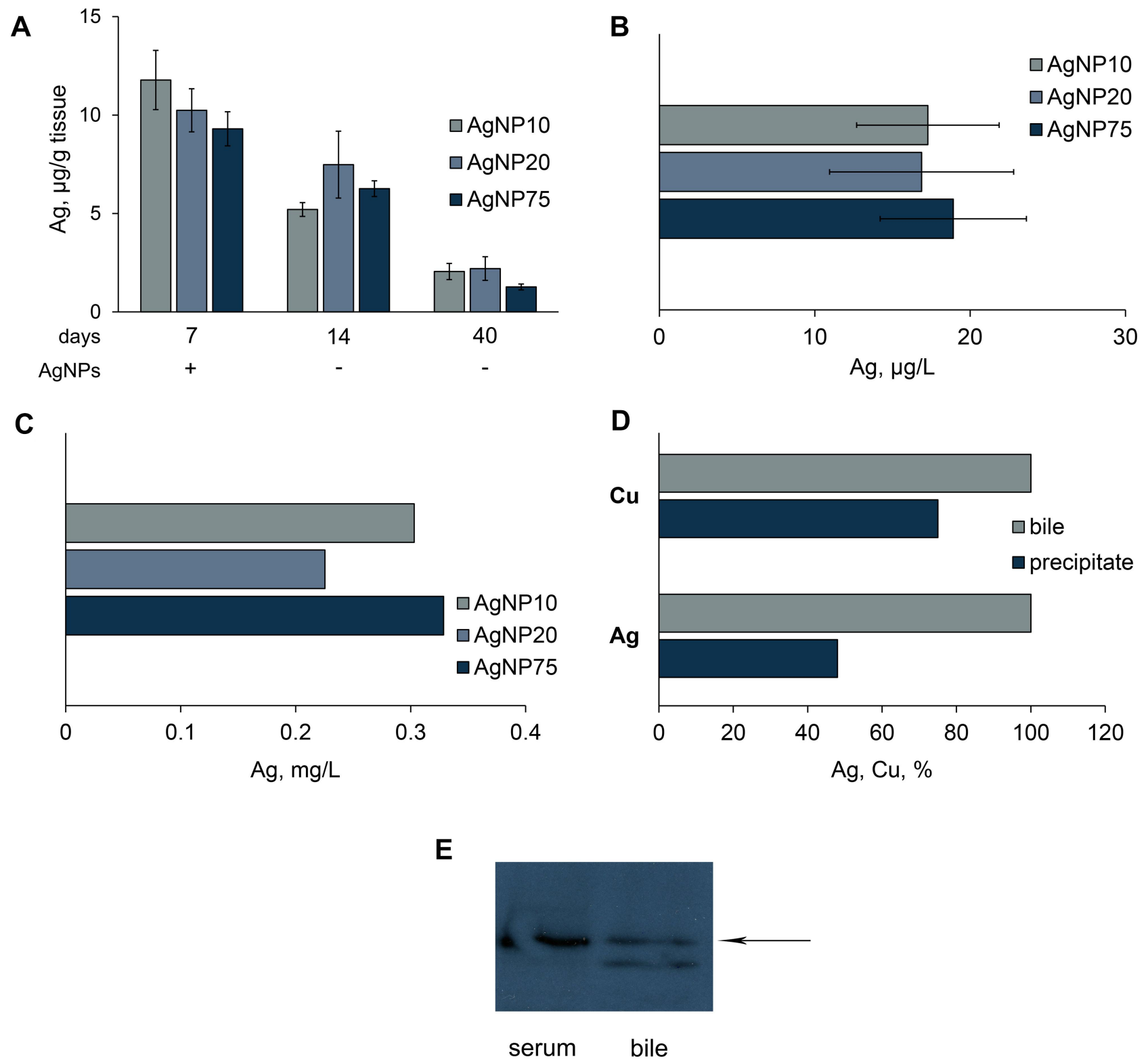

Figure 9 Excretion of silver from mice, treated with AgNPs. Dynamics of silver concentration in liver (A); detection of silver in urine (B), and bile (C). (D) fraction of copper and silver in bile, which is associated with $C_{p}(\%)$. Pools of bile samples were collected by a syringe from the gall bladders of mice, which received AgNP75 injections daily for seven days. $C_{P}$ was precipitated by antibodies to murine $C_{p}$. (E) blood serum $(0.1 \mu \mathrm{L})$ and bile $(10 \mu \mathrm{L})$ samples were subject to non-denaturing electrophoresis in 8\% PAG; the proteins were transferred to the membrane and analyzed with antibodies to murine $C_{p}$; arrow, position of oxidase murine blood serum $C_{p}$ in the gel.

The experiments show a pronounced negative correlation between dose- and time-dependent antibacterial activity and the diameter of the nanoparticles, which was observed even at small differences in diameter. The smaller the AgNPs were, the more biocidal they were for bacteria; likewise, larger particles were less effective as antibacterial agents (Figures 3 and 4). The difference in the viability of cells exposed to AgNP10 and AgNP75 reached 3 orders of magnitude. The antibacterial activity for the particles of the same size was strictly dosedependent, and the effect was stronger when bacterial cells were treated with $200 \mu \mathrm{M}$ AgNPs. These data obtained for $E$. coli cells are in agreement with the results obtained earlier for Vibrio natriegens, ${ }^{65}$ another Gramnegative bacterium. This is a good argument for the hypothesis that the action of AgNPs on bacteria is positively related to total surface area. Obviously, small particles have a larger chemically active surface at the same gross mass concentration than large ones. The biochemical and biophysical mechanisms of AgNPs' bactericidal properties are now being actively discussed. There are data that demonstrate the primary role of ROS formation during the 
degradation of AgNPs in their biocidal activity. ${ }^{24,25}$ It has also been shown, however, that AgNPs are not toxic when synthesized and tested in anaerobic conditions, which inhibit the corrosion and the oxidation of $\operatorname{Ag}(0)$ to $\mathrm{Ag}(\mathrm{I}){ }^{66}$ E. coli cells that express the extracellular metalbinding domain of human CTR1, which effectively chelates $\mathrm{Cu}(\mathrm{I}) / \mathrm{Ag}(\mathrm{I}) / \mathrm{Cu}(\mathrm{II})$, are much more resistant to bactericidal action of AgNPs than the parent strain. $\mathrm{Ag}(\mathrm{I})$ species, eg, originating from reactions of $\mathrm{AgNO}_{3} / \mathrm{AgCl}$ with biological media, are also known to be more toxic to bacteria than to mammalian cells in culture and to mammals in vivo. ${ }^{64}$ Thus, the formation of soluble $\mathrm{Ag}(\mathrm{I})$ species during biocorrosion is also an important (if not the primary) factor of AgNP bioactivity.

In the discussion of the relationship between AgNPs' ability to interfere in mammalian copper metabolism and nanoparticle size, the following points will be addressed.

\section{Dark Silver-Containing Inclusions Form in Mice Injected with AgNPs}

These inclusions can be seen by the naked eye and contain higher concentrations of silver than the surrounding tissue (Figure 5A and B). No obvious relationship was found between the inclusion formation and AgNP size. Earlier, extracellular silver deposits were detected with autometallographic staining and described in the lamina propria, between the epithelia and the lamina propria, and around the central veins and portal tracts in rats that received AgNPs orally. ${ }^{49}$ In addition, Juling et al, ${ }^{68}$ observed the formation de novo of secondary nanoparticles in rats after the oral ingestion of AgNPs. At present moment, it is not possible to determine if these inclusions contained metallic amorphous or nanocrystal silver. One possible mechanism for their formation may be the corrosion of initial AgNPs with the formation of soluble silver species and their transport and further conversion to insoluble species, such as $\mathrm{Ag}_{2} \mathrm{~S}$ or secondary $\mathrm{Ag}(0)$ nanoparticles. This possibility is supported by studies of the kinetics of $\operatorname{Ag}(\mathrm{I})$ and AgNP absorption by Chlamydomonas reinhardtii or by placenta ex vivo. ${ }^{69,70}$ We also previously observed electron-dense particles in $E$. coli bacteria that expressed extracellular N-terminus domain of CTR1, which were treated with silver nitrate. After 30 min exposure of bacteria to silver ions, the particles were formed. According to energy-dispersive X-ray spectroscopy and electron diffraction analyses, they contain crystal metallic silver and silver chloride. ${ }^{67}$ The data indicate the highly dynamic nature of
$\operatorname{Ag}(0) \leftrightarrow \operatorname{Ag}(\mathrm{I})$ redox equilibrium in a biological environment. This process may be qualified as nanoparticle formation de novo. It cannot be excluded that the formation of biogenic $\operatorname{Ag}(0)$ corpuscles may be a mechanism of detoxification for $\operatorname{Ag}(\mathrm{I})$ ions.

\section{The Nano-Silver is Non-Uniformly Distributed in the Body of Mice, and Its Distribution is Different from That of Copper}

The ability of organs to accumulate silver from AgNPs was measured at the end of 7-day treatment of mice with nanoparticles. There was no non-nanoparticulate silver in the AgNP samples, so nanoparticles were the only source of the silver in the tissues. In all studied organs, the silver content was independent of particle size but varied between organs (Figure 5C). The highest concentrations of silver were observed in the liver. These data correlate with earlier results for the analogous AgNP experiments in different animals. $^{71-73}$ as well as pulse-chase experiments with radioactive silver isotopes, where the metal was first detected in the liver and only then appeared in other organs. ${ }^{63}$ Moreover, in wild aquatic mammals, silver is accumulated predominantly in the liver, and its concentration increases in ontogenesis. ${ }^{74}$

AgNP treatment did not affect copper concentrations in the studied organs of mice (Figure 5D). The strong accumulation of both metals was manifested only in liver (Figure 5C and D). This may be related to the central role of the liver in in-body copper homeostasis: all of the absorbed copper is first transported to the liver. Part of this copper is secreted back into the bloodstream with $\mathrm{Cp}$, part of it remains in the hepatocytes as cofactors of cuproenzymes and metallothionein complexes, and another part is excreted through the bile. $^{75}$ High copper concentrations in the brain and heart are possibly explained by high levels of ubiquitous cuproenzymes (SOD1, COX1, glycosylphosphatidylinositol-Cp) or by tissue-specific cuproenzymes (peptidyl-glycine $\alpha$ amidating monooxygenase, copper-containing amine oxidases, dopamin- $\beta$-hydroxylase and so forth). Low concentrations of silver in the heart and brain may reflect the fact that silver cannot be inserted into these cuproenzymes, which have histidine-rich active sites favoring $\mathrm{Cu}(\mathrm{II})$ binding and $\mathrm{Cu}$ (II)/Cu(I) transition, but not $\mathrm{Cu}$ (I)/Ag(I) binding. ${ }^{37}$ Thus, silver is not inserted into apo-SOD1. Silver cannot reach COX, as COX17, which transports copper from cytosol to the location of formation of transmembrane holo-COX ensemble, does not bind $\operatorname{Ag}(\mathrm{I})$ (Figure 1). Another possibility 
cannot be ruled out, namely, that the organs may use different $\mathrm{Cu} / \mathrm{Ag}$ donors, membrane metal importers, and traffic pathways for copper delivery and thus accumulate copper and silver to different extents.

\section{Copper Status Indexes in the Blood Serum of Mice Treated with AgNPs Decrease Due to the Insertion of Silver in Cp Molecules}

Copper balance in blood serum is typically quantified by copper status indexes, which include atomic copper concentration, $\mathrm{Cp}$ oxidase activity, and concentration of immunoreactive $\mathrm{Cp}$ polypeptides. ${ }^{76}$ These indexes have different values in hereditary disorders of copper metabolism (Wilson disease, Menkes disease, aceruloplasminemia), as well as in neurodegenerative diseases (Parkinson's disease and Alzheimer's disease), inflammation, and cancer. Treatment of mice with AgNPs induced a 60\% decrease in copper concentration and a practical absence of $\mathrm{Cp}$ oxidase activity (Figure 6). As only $60 \%$ of copper is associated with $\mathrm{Cp}$ in mice (as compared with $95 \%$ in humans), ${ }^{77,78}$ it may be that seven-day ip treatment with AgNPs results in a complete replacement of the holo- $\mathrm{Cp}$ in circulation through inactive Ag-Cp molecules. The intervention of silver ions in $\mathrm{Cp}$ formation occurs during the metalation of newly synthesized $\mathrm{Cp}$ in the Golgi complex. ${ }^{79}$ It has previously been shown that $\mathrm{Cp}$ molecules that are synthesized in the liver under conditions of silver accumulation may have from one to four of their copper atoms replaced with silver. In all cases, Cp molecules lose their catalytic oxidase activities. ${ }^{60,80}$ The work of Jimenez-Arroyo et al, ${ }^{81}$ has revealed possible prerequisites of silver insertion to blue copper oxidase active sites through X-ray analyses. In this study, a crystal of hololaccase, whose active centers are a structural and functional analog for $\mathrm{Cp}$ catalytic centers, was soaked with silver ions. $\mathrm{Ag}(\mathrm{I})$ ions were coordinated with methionine residues along a distinct pathway from the protein surface to a cysteinecontaining blue copper site but could not displace copper from the site itself. Thus, the following hypothesis can be suggested. If an active site favors $\mathrm{Cu}$ (II) binding, and copper has to be oxidized prior to insertion into the active site, then $\operatorname{Ag}(\mathrm{I})$, which cannot oxidize, does not affect the formation of this site. If an active site favors $\mathrm{Cu}(\mathrm{I}) / \mathrm{Ag}(\mathrm{I})$ binding, $\mathrm{Cu}(\mathrm{I})$ and $\operatorname{Ag}(\mathrm{I})$ are inserted into the apo-enzyme on a first-come, first-served basis; once a metal ion is captured and an energetically stable coordination site is formed, no further displacement is possible. If the enzyme captures silver instead of copper, it becomes inactive due to the improper redox properties of $\operatorname{Ag}(\mathrm{I})$. In such cases, silver ions can impair the process of cuproenzyme formation, but they cannot affect the activity of already formed holo-cuproenzymes.

As AgNPs enter the organism, eg, during medical procedures, it is important to evaluate the possible negative consequences. In pioneering work by Liu et al, ${ }^{82}$ it was shown that under physiological conditions (close to those used in this work), incubation of AgNPs with Cp causes the loss of oxidase activity because of the replacement of copper ions by silver at the active centers of $\mathrm{Cp}$. Our observations are not consistent with these findings. We have shown instead that in vitro holo-Cp does not bind to AgNPs, silver does not displace copper in $\mathrm{Cp}$, all blue active sites are retained, and the oxidase activity of $\mathrm{Cp}$ is not affected either by AgNPs or their potential $\mathrm{Ag}(\mathrm{I})$ corrosion products (Figure 9). These data are in agreement with the results obtained for laccase. ${ }^{81}$ Moreover, Kirsipuu et al have persuasively shown that copper is bound to $\mathrm{Cp}$ in a nonexchangeable form. ${ }^{83}$ A possible source of inconsistency is the use of different Cp samples. The work of Liu et $\mathrm{al}^{82}$ used a commercial sample of $\mathrm{Cp}$ with no absorption at $610 \mathrm{~nm}$, which is a necessary feature of holo-Cp.

\section{AgNP Silver May Be Transported by a2MG in Murine Bloodstream}

In the blood serum of treated mice, a fraction of $\mathrm{Cp}$-bound silver was found together with another significant fraction of silver (Figure 7B, selecting rectangle); no more significant silver-containing fractions were present. In the latter fraction, polypeptides were found that corresponded by molecular mass to the subunit of $\alpha 2 \mathrm{MG}$ (former transcuprein, Figure $8 \mathrm{G}$ ). $\alpha 2 \mathrm{MG}$ is a mammalian blood serum protein that binds copper and silver ions and numerous cytokines and growth factors. ${ }^{59,84,85}$ It has been proposed that $\alpha 2 \mathrm{MG}$ is a transporter of absorbed copper and a copper donor for hepatocytes and for some nonhepatocyte cells. ${ }^{86}$ Thus, $\alpha 2 \mathrm{MG}$ could be the most probable target for in vitro and in vivo binding of nanoparticle silver and its potential transporter in circulation. Importantly, $\alpha 2 \mathrm{MG}$ can translocate between the bloodstream and the abdominal cavity, ${ }^{87}$ which makes it the best candidate for the role of absorbed nanoparticle silver transporter in vivo. $\alpha 2 \mathrm{MG}$ is a $720 \mathrm{kDa} \mathrm{N}$-glycoprotein that consists of four similar subunits, which are bound by S-S bridges. ${ }^{84}$ It is produced by liver and present at plasma levels of approximately $1.2 \mathrm{mg} / \mathrm{mL}^{88}$ (versus 
$0.36 \mathrm{mg} / \mathrm{mL}$ for $\mathrm{Cp}$ ). The main function of $\alpha 2 \mathrm{MG}$ is protease inhibitor action: it can inhibit, bait, and trap an enormous variety of proteinases. ${ }^{84}$ Once protease cleaves the bait site and is trapped by a conformation change in $\alpha 2 \mathrm{MG}$, the $\alpha 2 \mathrm{MG} /$ protease complex can be cleared from the plasma via liver low-density lipoprotein receptor related protein (LRP) through endocytosis. ${ }^{89}$ This route potentially allows $\alpha 2 \mathrm{MG}$ to deliver nanoparticle silver from the abdominal cavity (Figure 10A) or intestinal space (Figure 10B) to the endolysosomal compartment of hepatocytes. In lysosomes, low $\mathrm{pH}$ values facilitate the dissociation of nanoparticle silver, the forming $\operatorname{Ag}(\mathrm{I})$ ions are captured by vesicular copper transporter (CTR2) and transferred to the cytosol. In the cytosol, they are transferred to apo-ATOX1 and delivered to ATP7B, which pumps $\mathrm{Cu}(\mathrm{I}) / \mathrm{Ag}(\mathrm{I})$ into the lumen of the Golgi complex, where secretory $\mathrm{Cp}$ molecules are metalated, resulting in the formation of inactive Ag-Cp. Inside the cells, a fraction of $\operatorname{Ag}(\mathrm{I})$ is bound by metallothionein, and a fraction is transported by as-yet unknown means to the mitochondrial matrix and nuclei. This speculation is supported by observations indicating that nanoparticle silver

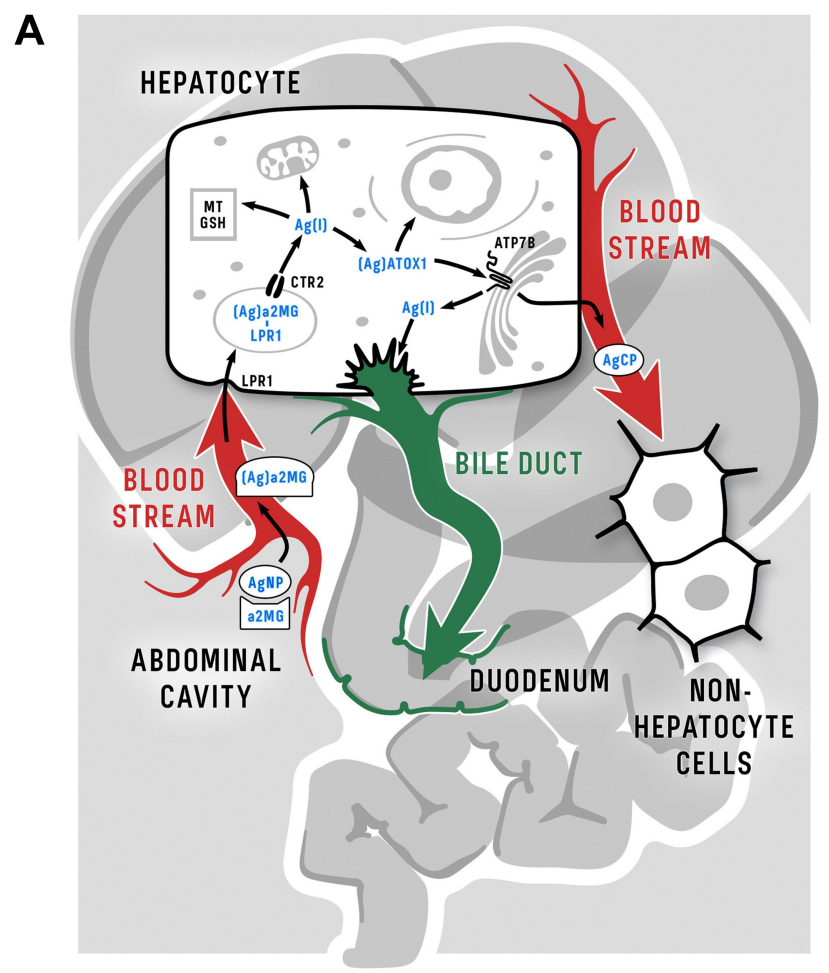

enters cells predominantly through clathrin-dependent endocytosis via a specific receptor or megalin-cubilin system and to a lesser extent by clathrin-independent caveolin-mediated endocytosis. ${ }^{90,91}$

\section{The Major Fraction of the Silver That Originates from $\mathrm{AgNPs}$ is Excreted Through the Bile with $C_{p}$}

At least 1 week after the last AgNPs, injection was needed for the significant decrease in specific silver concentration in liver (Figure 9A). The conclusion that silver is excreted in the bile corresponds well to earlier pulse-chase experiments (single intravenous injection of AgNPs with subsequent tracking of the resulting distribution throughout the organism for 7 days). ${ }^{56}$ The authors of the latter study demonstrated that in mice treated with nanoparticles, silver was observed in the bile in large quantities, and its concentration gradually decreased and almost returned to background in 7 days. There were few changes in silver concentration in the liver during the period of treatment with silver-containing nanoparticles. ${ }^{92}$ In rats that received AgNPs during subchronic oral treatment, silver was also excreted in the bile. ${ }^{49}$
B

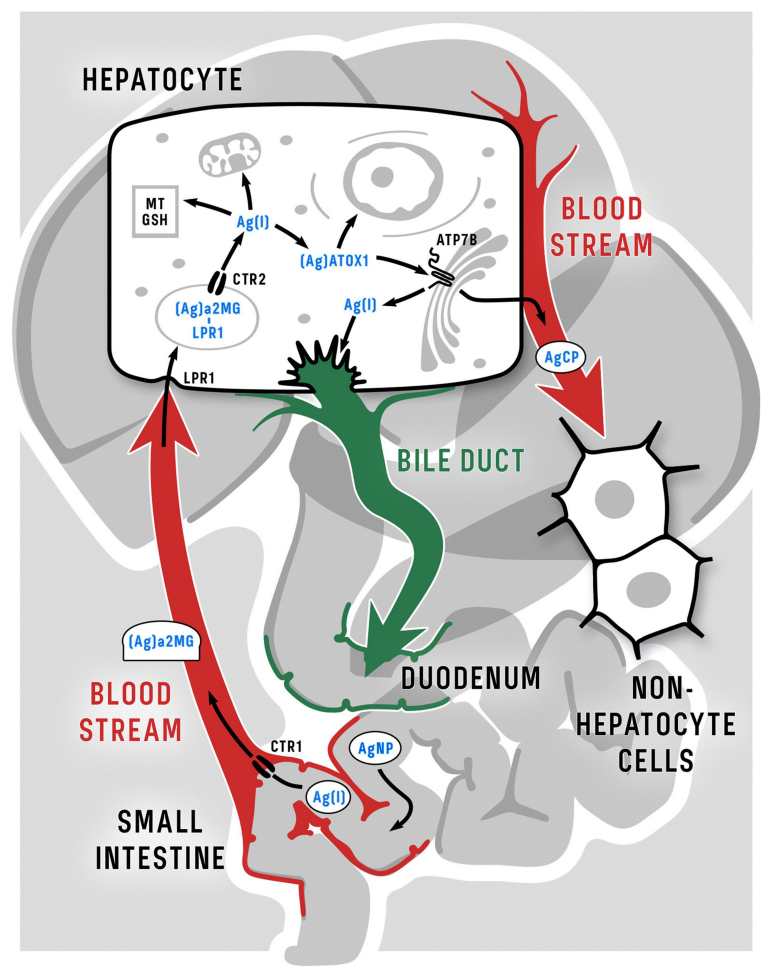

Figure 10 Schema of putative routes of nanoparticle silver following intraperitoneal (A) and oral (B) injection of AgNPs in mammalian organism and inside hepatocytes. The only difference between the intraperitoneal and oral delivery of silver from nanoparticles into the bloodstream is that silver is transported through enterocytes using CTRI when administered orally (see text for details). It should be noted that in humans, rats, and mice the roles of $\alpha 2 \mathrm{MG}$ in Cu(II) transport may be different; data from Hellman and Gitlin, ${ }^{63,}$ Cabrera et al, ${ }^{77}$ and Garcia-Ferrer et al. ${ }^{84}$ 
The observations indicated that after seven daily injections of nanoparticles, silver was present in urine (Figure 9B). In the two works cited above, silver was not found in the urine. ${ }^{49,92}$ This discrepancy could be explained by differences in the experimental setup. In our 7-day experiments, the liver could have been overloaded by silver, so its excess could not be completely excreted in the bile, leaving some silver to be excreted in the urine. This pattern resembles the copper excretion in the late stages of Wilson disease, when mutations in ATP7B result in the defect of $\mathrm{Cu}$ excretion in the bile and a subsequent copper overload in the liver. In such cases, copper is excreted in the urine as part of an unidentified small copper carrier. ${ }^{93}$ In pulse-chase experiments, an overload of silver in the liver might not be attained, while in experiments with subchronic oral treatment, silver concentrations in the urine were measured 1 day after the last AgNP treatment. At that point, the excretion of silver in the urine could have already been completed.

About $70 \%$ of copper and $50 \%$ of silver in the bile is associated with $\mathrm{Cp}$, as shown in immunoprecipitation experiments (Figure 9D). This experiment indicates that the major fraction of silver from AgNPs is excreted in atomic/ionic form. It has been known for several decades that two molecular forms of $\mathrm{Cp}$ are present in the protein fraction of human and rat bile. ${ }^{61,94}$ In this work, the same fact has been proven for the mouse (Figure 9E). One of these forms is probably desialated $\mathrm{Cp}$, which is recognized by a hepatic galactosespecific receptor and transferred to bile without modifications, possibly by transcytosis. This process serves as an excretion route and prevents further reabsorption of the copper. ${ }^{95}$

\section{Conclusion}

This work showed that AgNPs of definite size may display high antibacterial activity and reduced ability to disturb copper status and vice versa. This suggests that the current development of methods for creating AgNPs that combine minimal toxic properties for mammals and high economical value as antibacterial agents is promising. We focused on the intervention of AgNPs in mammalian copper metabolism. This intervention implies the chemical conversion of AgNPs to $\mathrm{Ag}(\mathrm{I})$ coordination compounds that enter the normal metabolism and can impair the activity of cuproenzymes. It is worth noting that some common neurodegenerative diseases are characterized by decreased copper status indexes, so the bioactivity of AgNPs in vivo may not be as neutral and omissible as it may seem. Moreover, the presented data allow us to conclude that AgNPs can be used for the controlled damping of copper status indexes in cases when low availability of copper is beneficial.

\section{Acknowledgments}

The authors thank Michael Rusakov for his help in the design of the graphical figures.

\section{Funding}

This work was supported by the Russian Science Foundation [grant number 20-74-10087] and Russian Foundation for Basic Research [grant numbers 18-5157811, 18-015-00481, 19-315-90129].

\section{Disclosure}

Ekaterina Yu Ilyechova report grants from the Russian Science Foundation and Russian Foundation for Basic Research, during the conduct of the study. The authors report no other potential conflicts of interest in this work.

\section{References}

1. Yaqoob SB, Adnan R, Rameez Khan RM, Rashid M. Gold, silver, and palladium nanoparticles: A chemical tool for biomedical applications. Front Chem. 2020;8:376.

2. Zhang XF, Liu ZG, Shen W, Gurunathan S. Silver nanoparticles: synthesis, characterization, properties, applications, and therapeutic approaches. Int J Mol Sci. 2016;17(9):1534. doi:10.3390/ijms17 091534

3. Elbehiry A, Al-Dubaib M, Marzouk E, Moussa I. Antibacterial effects and resistance induction of silver and gold nanoparticles against Staphylococcus aureus-induced mastitis and the potential toxicity in rats. Microbiologyopen. 2019;8(4):e00698. doi:10.1002/ mbo3.698

4. Chowdhury NR, MacGregor-Ramiasa M, Zilm P, Majewski P, Vasilev K. 'Chocolate' silver nanoparticles: synthesis, antibacterial activity and cytotoxicity. J Colloid Interface Sci. 2016;482:151-158. doi:10.1016/j.jcis.2016.08.003

5. Rodrigues CT, de Andrade FB, de Vasconcelos LRSM, et al. Antibacterial properties of silver nanoparticles as a root canal irrigant against Enterococcus faecalis biofilm and infected dentinal tubules. Int Endod J. 2018;51(8):901-911. doi:10.1111/iej.12904

6. Durán N, Nakazato G, Seabra AB. Antimicrobial activity of biogenic silver nanoparticles, and silver chloride nanoparticles: an overview and comments. Appl Microbiol Biotechnol. 2016;100(15):6555-6570. doi:10.1007/s00253-016-7657-7

7. You J, Zhang Y, Hu Z. Bacteria and bacteriophage inactivation by silver and zinc oxide nanoparticles. Colloids Surf B Biointerfaces. 2011;85(2):161-167. doi:10.1016/j.colsurfb.2011.02.023

8. Xiang D, Zheng Y, Duan W, et al. Inhibition of A/Human/Hubei/3/ 2005 (H3N2) influenza virus infection by silver nanoparticles in vitro and in vivo [published correction appears. Int $J$ Nanomedicine. 2013;8:4703. doi:10.2147/IJN.S57432

9. Franci G, Falanga A, Galdiero S, et al. Silver nanoparticles as potential antibacterial agents. Molecules. 2015;20(5):8856-8874. doi:10.3390/molecules20058856

10. Gliga AR, Skoglund S, Wallinder IO, Fadeel B, Karlsson HL. Sizedependent cytotoxicity of silver nanoparticles in human lung cells: the role of cellular uptake, agglomeration and Ag release. Part Fibre Toxicol. 2014;11:11. doi:10.1186/1743-8977-11-11 
11. Akter M, Sikder MT, Rahman MM, et al. A systematic review on silver nanoparticles-induced cytotoxicity: physicochemical properties and perspectives. $J$ Adv Res. 2017;9:1-16. doi:10.1016/j.jare.20 17.10 .008

12. Xin L, Wang J, Fan G, et al. Oxidative stress and mitochondrial injury-mediated cytotoxicity induced by silver nanoparticles in human A549 and HepG2 cells. Environ Toxicol. 2016;31 (12):1691-1699. doi:10.1002/tox.22171

13. Begum AN, Aguilar JS, Elias L, Hong Y. Silver nanoparticles exhibit coating and dose-dependent neurotoxicity in glutamatergic neurons derived from human embryonic stem cells. Neurotoxicology. 2016;57:45-53. doi:10.1016/j.neuro.2016.08.015

14. Tang S, Zheng J. Antibacterial activity of silver nanoparticles: structural effects. Adv Healthc Mater. 2018;7(13):e1701503. doi:10.1002/ adhm. 201701503

15. Pratsinis A, Hervella P, Leroux JC, Pratsinis SE, Sotiriou GA. Toxicity of silver nanoparticles in macrophages. Small. 2013;9 (15):2576-2584. doi:10.1002/smll.201202120

16. Soares T, Ribeiro D, Proença C, Chisté RC, Fernandes E, Freitas M. Size-dependent cytotoxicity of silver nanoparticles in human neutrophils assessed by multiple analytical approaches. Life Sci. 2016;145:247-254. doi:10.1016/j.lfs.2015.12.046

17. Liu J, Li S, Fang Y, Zhu Z. Boosting antibacterial activity with mesoporous silica nanoparticles supported silver nanoclusters. $J$ Colloid Interface Sci. 2019;555:470-479. doi:10.1016/j.jcis.2019.08.009

18. Raj A, Shah P, Agrawal N. Dose-dependent effect of silver nanoparticles (AgNPs) on fertility and survival of Drosophila: an in-vivo study. PLoS One. 2017;12(5):e0178051. doi:10.1371/journal.pone.0178051

19. Ottoni CA, Lima Neto MC, Léo P, Ortolan BD, Barbieri E, De Souza AO. Environmental impact of biogenic silver nanoparticles in soil and aquatic organisms. Chemosphere. 2020;239:124698. doi:10.1016/j.chemosphere.2019.124698

20. Abramenko N, Demidova TB, Krutyakov YA, et al. The effect of capping agents on the toxicity of silver nanoparticles to Danio rerio embryos. Nanotoxicology. 2019;13(1):1-13. doi:10.1080/17435390. 2018.1498931

21. Caloudova H, Hodkovicova N, Sehonova P, et al. The effect of silver nanoparticles and silver ions on zebrafish embryos (Danio rerio). Neuro Endocrinol Lett. 2018;39(4):299-304.

22. Roh JY, Sim SJ, Yi J, et al. Ecotoxicity of silver nanoparticles on the soil nematode Caenorhabditis elegans using functional ecotoxicogenomics. Environ Sci Technol. 2009;43(10):3933-3940. doi:10.1021/es $803477 \mathrm{u}$

23. Munger MA, Radwanski P, Hadlock GC, et al. In vivo human time-exposure study of orally dosed commercial silver nanoparticles. Nanomedicine. 2014;10(1):1-9. doi:10.1016/j.nano.20 13.06.010

24. Pareek V, Gupta R, Panwar J. Do physico-chemical properties of silver nanoparticles decide their interaction with biological media and bactericidal action? A review. Mater Sci Eng C Mater Biol Appl. 2018;90:739-749. doi:10.1016/j.msec.2018.04.093

25. Dakal TC, Kumar A, Majumdar RS, Yadav V. Mechanistic basis of antimicrobial actions of silver nanoparticles. Front Microbiol. 2016;7:1831. doi:10.3389/fmicb.2016.01831

26. Kozlowski H, Kolkowska P, Watly J, Krzywoszynska K, Potocki S. General aspects of metal toxicity. Curr Med Chem. 2014;21 (33):3721-3740. doi:10.2174/0929867321666140716093838

27. Linder MC. Copper and genomic stability in mammals. Mutat Res. 2001;475(1-2):141-152. doi:10.1016/S0027-5107(01)00076-8

28. Jiménez-Lamana J, Laborda F, Bolea E, et al. An insight into silver nanoparticles bioavailability in rats. Metallomics. 2014;6 (12):2242-2249. doi:10.1039/C4MT00200H

29. Orlov IA, Sankova TP, Babich PS, et al. New silver nanoparticles induce apoptosis-like process in E. coli and interfere with mammalian copper metabolism. Int $J$ Nanomedicine. 2016;11:6561-6574. doi:10.2147/IJN.S117745
30. Pavelková M, Vysloužil J, Kubová K, Vetchý D. Biological role of copper as an essential trace element in the human organism. Biologická role mědi jako základního stopového prvku v lidském organismu. Ceska Slov Farm. 2018;67(4):143-153.

31. Yuan S, Chen S, Xi Z, Liu Y. Copper-finger protein of Sp1: the molecular basis of copper sensing. Metallomics. 2017;9(8):11 69-1175. doi:10.1039/C7MT00184C

32. D'Ambrosi N, Rossi L. Copper at synapse: release, binding and modulation of neurotransmission. Neurochem Int. 2015;90:36-45. doi:10.1016/j.neuint.2015.07.006

33. Li S, Ahmed L, Zhang R, et al. Smelling sulfur: copper and silver regulate the response of human odorant receptor OR2T11 to low-molecular-weight thiols. $J$ Am Chem Soc. 2016;138(40):13 281-13288. doi: $10.1021 /$ jacs.6b06983

34. Riera-Romo M. COMMD1: A multifunctional regulatory protein. $J$ Cell Biochem. 2018;119(1):34-51. doi:10.1002/jcb.26151

35. Kaplan JH, Lutsenko S. Copper transport in mammalian cells: special care for a metal with special needs. J Biol Chem. 2009;284 (38):25461-25465. doi:10.1074/jbc.R109.031286

36. Bhattacharjee A, Chakraborty K, Shukla A. Cellular copper homeostasis: current concepts on its interplay with glutathione homeostasis and its implication in physiology and human diseases. Metallomics. 2017;9(10):1376-1388. doi:10.1039/C7MT00066A

37. Puchkova LV, Broggini M, Polishchuk EV, Ilyechova EY, Polishchuk RS. Silver ions as a tool for understanding different aspects of copper metabolism. Nutrients. 2019;11(6):1364. doi:10.3390/nu11061364

38. Logeman BL, Wood LK, Lee J, Thiele DJ. Gene duplication and neo-functionalization in the evolutionary and functional divergence of the metazoan copper transporters Ctr1 and Ctr2. J Biol Chem. 2017;292(27):11531-11546. doi:10.1074/jbc.M117.793356

39. Zimnicka AM, Ivy K, Kaplan JH. Acquisition of dietary copper: a role for anion transporters in intestinal apical copper uptake. Am J Physiol Cell Physiol. 2011;300(3):C588-C599. doi:10.1152/ajpcell.00054.2010

40. Kluska K, Peris-Díaz MD, Płonka D, et al. Formation of highly stable multinuclear $\mathrm{Ag}_{\mathrm{n}} \mathrm{S}_{\mathrm{n}}$ clusters in zinc fingers disrupts their structure and function. Chem Commun. 2020;56(9):1329-1332. doi:10.1039/ C9CC09418K

41. Berridge MV, Herst PM, Tan AS. Tetrazolium dyes as tools in cell biology: new insights into their cellular reduction. Biotechnol Annu Rev. 2005;11:127-152.

42. Owen J, Smith H. Detection of ceruloplasmin after zone electrophoresis. Clin Chim Acta. 1961;6:441-444. doi:10.1016/00098981(61)90074-2

43. Reitman S, Frankel S. A colorimetric method for the determination of serum glutamic oxalacetic and glutamic pyruvic transaminases. $\mathrm{Am}$ J Clin Pathol. 1957;28(1):56-63. doi:10.1093/ajcp/28.1.56

44. Zatulovskaia YA, Ilyechova EY, Puchkova LV. The features of copper metabolism in the rat liver during development. PLoS One. 2015;10 (10):e0140797. doi:10.1371/journal.pone.0140797

45. Sokolov AV, Kostevich VA, Romanico DN, Zakharova ET, Vasilyev VB. Two-stage method for purification of ceruloplasmin based on its interaction with neomycin. Biochemistry (Mosc). 2012;77(6):631-638. doi:10.1134/S0006297912060107

46. Samygina VR, Sokolov AV, Bourenkov G, et al. Rat ceruloplasmin: a new labile copper binding site and zinc/copper mosaic. Metallomics. 2017;9(12):1828-1838. doi:10.1039/C7MT00157F

47. Sharma M, Mohapatra S, Ranjann S, Dasgupta N, Kumar R, Thomas S. Transdermal and intravenous nano drug delivery systems. Appl Targeted Nano Drugs Delivery Systems. 2019;499-550.

48. Hadrup N, Loeschner K, Bergström A, et al. Subacute oral toxicity investigation of nanoparticulate and ionic silver in rats. Arch Toxicol. 2012;86(4):543-551. doi:10.1007/s00204-011-0759-1

49. Loeschner K, Hadrup N, Qvortrup K, et al. Distribution of silver in rats following 28 days of repeated oral exposure to silver nanoparticles or silver acetate. Part Fibre Toxicol. 2011;8:18. doi:10.1186/1743-8977$8-18$ 
50. Katsnelson BA, Privalova LI, Sutunkova MP, et al. Some inferences from in vivo experiments with metal and metal oxide nanoparticles: the pulmonary phagocytosis response, subchronic systemic toxicity and genotoxicity, regulatory proposals, searching for bioprotectors (a self-overview). Int J Nanomedicine. 2015;10:3013-3029. doi:10.21 47/IJN.S80843

51. Kim YS, Song MY, Park JD, et al. Subchronic oral toxicity of silver nanoparticles. Part Fibre Toxicol. 2010;7:20. doi:10.1186/1743-89777-20

52. Zhang Y, Wu D, Zhang X, Ma N, Liu Y. MicroRNA sponge knockdowns miR-483-5p and upregulates serum ALT/AST in transgenic mice. Biochemistry. 2018;83(1):54-59. doi:10.1134/S0006297918010078

53. Aldubayan MA, Elgharabawy RM, Ahmed AS, Tousson E. Antineoplastic activity and curative role of avenanthramides against the growth of ehrlich solid tumors in mice. Oxid Med Cell Longev. 2019;2019:5162687. doi:10.1155/2019/5162687

54. Recordati C, De Maglie M, Bianchessi S, et al. Tissue distribution and acute toxicity of silver after single intravenous administration in mice: nano-specific and size-dependent effects. Part Fibre Toxicol. 2016;13:12. doi:10.1186/s12989-016-0124-X

55. Ilyechova EY, Saveliev AN, Skvortsov AN, et al. The effects of silver ions on copper metabolism in rats. Metallomics. 2014;6 (10):1970-1987. doi:10.1039/C4MT00107A

56. Rózga M, Sokołowska M, Protas AM, Bal W. Human serum albumin coordinates $\mathrm{Cu}(\mathrm{II})$ at its $\mathrm{N}$-terminal binding site with $1 \mathrm{pM}$ affinity. J Biol Inorg Chem. 2007;12(6):913-918.

57. Gonzalez P, Bossak K, Stefaniak E, et al. N-terminal cu-binding motifs (Xxx-Zzz-His, Xxx-His) and their derivatives: chemistry, biology and medicinal applications. Chemistry. 2018;24(32): 8029-8041. doi:10.1002/chem.201705398

58. Sottrup-Jensen L, Stepanik TM, Kristensen T, et al. Primary structure of human alpha 2-macroglobulin. V. The complete structure. J Biol Chem. 1984;259(13):8318-8327.

59. Hanson SR, Donley SA, Linder MC. Transport of silver in virgin and lactating rats and relation to copper. J Trace Elem Med Biol. 2001;15 (4):243-253. doi:10.1016/S0946-672X(01)80040-7

60. Harada M, Sakisaka S, Yoshitake M, et al. Biliary copper excretion in acutely and chronically copper-loaded rats. Hepatology. 1993;17 (1):111-117. doi:10.1002/hep.1840170120

61. Verbina IA, Puchkova LV, Gaitskhoki VS, Neifakh SA. Isolation and partial characterization of molecular forms of ceruloplasmin from human bile. FEBS Lett. 1992;298(2-3):105-108. doi:10.1016/00145793(92)80032-C

62. Chowrimootoo GF, Ahmed HA, Seymour CA. New insights into the pathogenesis of copper toxicosis in Wilson's disease: evidence for copper incorporation and defective canalicular transport of caeruloplasmin. Biochem J. 1996;315((Pt 3)(Pt 3)):851-855. doi:10.1042/ bj3150851

63. Hellman NE, Gitlin JD. Ceruloplasmin metabolism and function. Annu Rev Nutr. 2002;22:439-458. doi:10.1146/annurev.nutr.22.012502.114457

64. Kędziora A, Speruda M, Krzyżewska E, Rybka J, Łukowiak A, Bugla-Płoskońska G. Similarities and differences between silver ions and silver in nanoforms as antibacterial agents. Int J Mol Sci. 2018;19(2):444. doi:10.3390/ijms19020444

65. Dong Y, Zhu H, Shen Y, Zhang W, Zhang L. Antibacterial activity of silver nanoparticles of different particle size against Vibrio Natriegens. PLoS One. 2019;14(9):e0222322. doi:10.1371/journal. pone.0222322

66. Le Ouay B, Stellacci F. Antibacterial activity of silver nanoparticles: A surface science insight. Nano Today. 2015;10(3):339-354. doi:10. 1016/j.nantod.2015.04.002

67. Sankova TP, Orlov IA, Saveliev AN, et al. The extracellular domain of human high affinity copper transporter (hNdCTR1), synthesized by E. coli cells, chelates silver and copper ions in vivo. Biomolecules. 2017;7(4):78. doi:10.3390/biom7040078
68. Juling $S$, Bachler $G$, von Götz $N$, et al. In vivo distribution of nanosilver in the rat: the role of ions and de novo-formed secondary particles. Food Chem Toxicol. 2016;97:327-335. doi:10.1016/j.fct.20 16.08.016

69. Leclerc S, Wilkinson KJ. Bioaccumulation of Nanosilver by Chlamydomonas reinhardtii-nanoparticle or the free ion? Environ Sci Technol. 2014;48(1):358-364. doi:10.1021/es404037z

70. Vidmar J, Loeschner K, Correia M, et al. Translocation of silver nanoparticles in the ex vivo human placenta perfusion model characterized by single particle ICP-MS. Nanoscale. 2018;10(25):11 980-11991.

71. Bruneau A, Turcotte P, Pilote M, Gagné F, Gagnon C. Fate of silver nanoparticles in wastewater and immunotoxic effects on rainbow trout. Aquat Toxicol. 2016;174:70-81. doi:10.1016/j.aquatox.2016. 02.013

72. Rezaei A, Farzinpour A, Vaziry A, Jalili A. Effects of silver nanoparticles on hematological parameters and hepatorenal functions in laying japanese Quails. Biol Trace Elem Res. 2018;185(2):475-485. doi:10.1007/s12011-018-1267-4

73. El Mahdy MM, Eldin TA, Aly HS, Mohammed FF, Shaalan MI. Evaluation of hepatotoxic and genotoxic potential of silver nanoparticles in albino rats. Exp Toxicol Pathol. 2015;67(1):21-29. doi:10.10 16/j.etp.2014.09.005

74. Saeki K, Nakajima M, Loughlin TR, et al. Accumulation of silver in the liver of three species of pinnipeds. Environ Pollut. 2001;112 (1):19-25. doi:10.1016/S0269-7491(00)00103-2

75. Cousins RJ. Absorption, transport, and hepatic metabolism of copper and zinc: special reference to metallothionein and ceruloplasmin. Physiol Rev. 1985;65(2):238-309. doi:10.1152/physrev.1985.65.2. 238

76. Harvey LJ, McArdle HJ. Biomarkers of copper status: a brief update. Br J Nutr. 2008;99(Suppl 3):S10-S13. doi:10.1017/S00071145080 06806

77. Cabrera A, Alonzo E, Sauble E, et al. Copper binding components of blood plasma and organs, and their responses to influx of large doses of (65) $\mathrm{Cu}$, in the mouse. Biometals. 2008;21(5):525-543. doi:10. 1007/s10534-008-9139-6

78. Bernevic B, El-Khatib AH, Jakubowski N, Weller MG. Online immunocapture ICP-MS for the determination of the metalloprotein ceruloplasmin in human serum. BMC Res Notes. 2018;11(1):213. doi:10.1186/s13104-018-3324-7

79. Hellman NE, Kono S, Mancini GM, Hoogeboom AJ, De Jong GJ, Gitlin JD. Mechanisms of copper incorporation into human ceruloplasmin. J Biol Chem. 2002;277(48):46632-46638.

80. Hirasawa F, Kawarada Y, Sato M, et al. The effect of silver administration on the biosynthesis and the molecular properties of rat ceruloplasmin. Biochim Biophys Acta. 1997;1336(2):195-201. doi:10.1016/S0304-4165(97)00026-3

81. Jimenez-Arroyo N, Cardona-Felix CS, Rojas-Trejo SP, RudinoPinera E. Structural function of the methionine-rich beta-hairpin in the laccase for T. Thermophilus. 2020.

82. Liu W, Worms IAM, Herlin-Boime N, et al. Interaction of silver nanoparticles with metallothionein and ceruloplasmin: impact on metal substitution by $\mathrm{Ag}(\mathrm{i})$, corona formation and enzymatic activity. Nanoscale. 2017;9(19):6581-6594. doi:10.1039/C7NR010 $75 \mathrm{C}$

83. Kirsipuu T, Zadorožnaja A, Smirnova J, et al. Copper(II)-binding equilibria in human blood. Sci Rep. 2020;10(1):5686. doi:10.1038/ s41598-020-62560-4

84. Garcia-Ferrer I, Marrero A, Gomis-Rüth FX, Goulas T. $\alpha_{2-}$ macroglobulins: structure and function. Subcell Biochem. 2017; 83:149-183.

85. Liu N, Lo LS, Askary SH, et al. Transcuprein is a macroglobulin regulated by copper and iron availability. J Nutr Biochem. 2007;18 (9):597-608. doi:10.1016/j.jnutbio.2006.11.005 
86. Moriya M, Ho YH, Grana A, et al. Copper is taken up efficiently from albumin and alpha2-macroglobulin by cultured human cells by more than one mechanism. Am J Physiol Cell Physiol. 2008;295(3): C708-C721. doi:10.1152/ajpcell.00029.2008

87. Isaac L, Florido MP, Fecchio D, Singer LM. Murine alpha-2-macroglobulin increase during inflammatory responses and tumor growth. Inflamm Res. 1999;48(8):446-452. doi:10.1007/ s000110050485

88. Coan MH, Roberts RC. A redetermination of the concentration of alpha 2-macroglobulin in human plasma. Biol Chem Hoppe Seyler. 1989;370(7):673-676.

89. Lillis AP, Mikhailenko I, Strickland DK. Beyond endocytosis: LRP function in cell migration, proliferation and vascular permeability. J Thromb Haemost. 2005;3(8):1884-1893. doi:10.1111/j.1538-7836. 2005.01371.x

90. Zhao F, Zhao Y, Liu Y, Chang X, Chen C, Zhao Y. Cellular uptake, intracellular trafficking, and cytotoxicity of nanomaterials. Small. 2011;7(10):1322-1337. doi:10.1002/smll.201100001

91. Panzarini E, Mariano S, Carata E, Mura F, Rossi M, Dini L. Intracellular transport of silver and gold nanoparticles and biological responses: an update. Int J Mol Sci. 2018;19(5):1305. doi:10.3390/ ijms19051305
92. Sakurai Y, Tada H, Gonda K, et al. Development of silica-coated silver iodide nanoparticles and their biodistribution. Tohoku J Exp Med. 2012;228(4):317-323. doi:10.1620/tjem.228.317

93. Gray LW, Peng F, Molloy SA, et al. Urinary copper elevation in a mouse model of Wilson's disease is a regulated process to specifically decrease the hepatic copper load. PLoS One. 2012;7(6):e38327. doi:10.1371/journal.pone.0038327

94. Puchkova LV, Aleĭnikova TD, Verbina IA, Zakharova ET, Pliss MG, Gaĭtskhoki VS. Biosintez dvukh molekuliarnykh form tseruloplazmina $\mathrm{v}$ pecheni krysy i ikh poliarnaia sekretsiia v krovotok i v zhelch' [Biosynthesis of two molecular forms of ceruloplasmin in rat liver and their polar secretion into the blood stream and bile]. Biokhimiia. 1993;58(12):1893-1901.

95. Gregoriadis G, Morell AG, Sternlieb I, Scheinberg IH. Catabolism of desialylated ceruloplasmin in the liver. J Biol Chem. 1970;245 (21):5833-5837.

\section{Publish your work in this journal}

Nanotechnology, Science and Applications is an international, peerreviewed, open access journal that focuses on the science of nanotechnology in a wide range of industrial and academic applications. It is characterized by the rapid reporting across all sectors, including engineering, optics, bio-medicine, cosmetics, textiles, resource sustainability and science. Applied research into nano-materials, particles, nano-structures and fabrication, diagnostics and analytics, drug delivery and toxicology constitute the primary direction of the journal. The manuscript management system is completely online and includes a very quick and fair peer-review system, which is all easy to use. Visit http://www.dovepress.com/testimonials.php to read real quotes from published authors. 